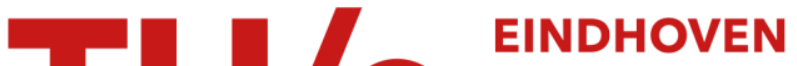 UNIVERSITY OF TECHNOLOGY
}

\section{The role of interface and fiber anisotropy in controlling the performance of polyethylene-fibre-reinforced composites}

\section{Citation for published version (APA):}

Peijs, A. A. J. M., Rijsdijk, H. A., Kok, de, J. M. M., \& Lemstra, P. J. (1994). The role of interface and fiber anisotropy in controlling the performance of polyethylene-fibre-reinforced composites. Composites Science and Technology, 52(3), 449-466. https://doi.org/10.1016/0266-3538(94)90180-5

DOI:

10.1016/0266-3538(94)90180-5

Document status and date:

Published: 01/01/1994

\section{Document Version:}

Publisher's PDF, also known as Version of Record (includes final page, issue and volume numbers)

\section{Please check the document version of this publication:}

- A submitted manuscript is the version of the article upon submission and before peer-review. There can be important differences between the submitted version and the official published version of record. People interested in the research are advised to contact the author for the final version of the publication, or visit the $\mathrm{DOI}$ to the publisher's website.

- The final author version and the galley proof are versions of the publication after peer review.

- The final published version features the final layout of the paper including the volume, issue and page numbers.

Link to publication

\section{General rights}

Copyright and moral rights for the publications made accessible in the public portal are retained by the authors and/or other copyright owners and it is a condition of accessing publications that users recognise and abide by the legal requirements associated with these rights.

- Users may download and print one copy of any publication from the public portal for the purpose of private study or research.

- You may not further distribute the material or use it for any profit-making activity or commercial gain

- You may freely distribute the URL identifying the publication in the public portal.

If the publication is distributed under the terms of Article 25fa of the Dutch Copyright Act, indicated by the "Taverne" license above, please follow below link for the End User Agreement:

www.tue.nl/taverne

Take down policy

If you believe that this document breaches copyright please contact us at:

openaccess@tue.nl

providing details and we will investigate your claim. 


\title{
THE ROLE OF INTERFACE AND FIBRE ANISOTROPY IN CONTROLLING THE PERFORMANCE OF POLYETHYLENE- FIBRE-REINFORCED COMPOSITES
}

\author{
T. Peijs, H. A. Rijsdijk, J. M. M. de Kok \& P. J. Lemstra \\ Centre for Polymers and Composites, Eindhoven University of Technology, PO Box 513, 5600 MB Eindhoven, \\ The Netherlands
}

(Received 25 February 1994; revised version received 1 June 1994; accepted 21 June 1994)

\begin{abstract}
The influence of the interface and fibre anisotropy on the performance of high-performance polyethylene (HP-PE)/epoxy composites was investigated. It was concluded that the relatively low experimentally found maximum values for shear and transverse strength of HP-PE/epoxy composites, incorporating surface treated fibres, are caused by a change in failure mode from debonding to fibre splitting with increasing levels of adhesion. To obtain more quantitative information about the role of fibre anisotropy on the strength of HP-PE composites, a micromechanical analysis was utilized to predict ultimate composite properties. Theoretical values for composite strength as obtained via micromechanics, assuming perfect adhesion, are in good agreement with experimental data for HP-PE composites incorporating plasma treated fibres, indicating that the highly anisotropic character of HP-PE fibres plays a predominant role in the structural performance of composites based on these fibres.
\end{abstract}

Keywords: composite, polyethylene fibre, epoxy, adhesion, fibre anisotropy, failure mechanisms, micromechanics, off-axis strength

\section{INTRODUCTION}

High-performance polyethylene (HP-PE) fibres possess excellent short-term mechanical properties such as stiffness and strength, ${ }^{1}$ whereas long-term properties such as creep are generally poor. ${ }^{2,3}$ Because of the unique short-term properties, main developments for their use in advanced composites are limited to reinforcements for impact or ballistic resistant composite structures. $^{3-5}$

Few developments are aimed at structural applications and on the basis of experience with composite systems such as glass/epoxy and carbon/epoxy it was generally assumed that limiting properties such as transverse, shear and compressive strength were mainly caused by the poor interfacial bond strength between the apolar and smooth HP-PE fibres and polymer matrices. ${ }^{6}$ Consequently, surface modification of HP-PE fibres aimed at improved adhesion to polymer matrices has been, and still is, the subject of numerous studies. ${ }^{7-28}$

Besides adhesion, however, another important aspect with respect to composite performance is the pronounced anisotropic character of these highly oriented HP-PE fibres. As a consequence of this anisotropy, one focuses automatically on exploiting maximum strength and stiffness in one direction, i.e. fibres that are typical one-dimensional (1-D) structures. Unfortunately, however, in the case of fibre-reinforced composites this highly anisotropic character can be a major disadvantage in off-axis (transverse, shear) or compressive loadings.

These aspects are the topics investigated in this paper, focusing on off-axis stiffness and strength, the longitudinal, transverse and shear strength and, finally, the compressive strength of unidirectional composites, respectively.

\subsection{Fibre/matrix adhesion}

The excellent chemical stability (although an advantage in many respects), the absence of polar groups, and the low surface energy of PE fibres is conflicting with a good bond between fibre and polymer matrix. Since it is generally recognized that the level of fibre/matrix adhesion is the key factor for an optimum translation of fibre properties to composite performance, many attempts have been made to improve the structural applicability of composites based on HP-PE fibres by improving the bond strength between this fibre and polymer matrices. Therefore, a number of oxidizing surface treatments have been developed, including chemical etching, corona and plasma treatments.

The first attempt to improve the adhesion of oriented PE structures was undertaken by Ladizesky and Ward, ${ }^{7}$ who investigated the effect of plasma and chromic acid treatment on the pull-out strength of melt-spun/drawn PE fibres to an epoxy matrix. 
Although both treatments were effective in raising the bond strength, plasma treatment using oxygen as a carrier gas was the most effective, resulting in a change in failure mode from sliding along the interface to rupture within the fibre. According to the authors this change in failure mode was a result of the cellular structure on the fibre surface, as observed after plasma treatment, which should result in mechanical interlocking between fibre and resin. Subsequent publications also reported the effect of chromic acid and plasma treatments on composite properties incorporating melt-spun PE fibres..$^{8-12}$ The authors stated that the interlaminar shear strength (ILSS) of composites based on melt-spun PE fibres can be substantially increased from $11 \mathrm{MPa}$ for untreated fibres to $27 \mathrm{MPa}$ for composites with plasma-etched fibres. ${ }^{10.11}$

Investigations on the effect of surface treatments on the bond strength of gel-spun PE fibres and epoxy matrices started at the mid-1980s. Developments focused mainly on industrial processes such as corona and plasma treatments. Corona discharge was reported to result in an approximately two-fold increase in adhesion ${ }^{13-15}$ with typical ILSS values of 18 to $20 \mathrm{MPa}$ versus 8 to $14 \mathrm{MPa}$ for untreated fibres. Plasma surface treatments of gel-spun PE fibres were reported to result in an even more substantial increase in adhesion. ${ }^{15-24}$ Gas mixtures containing oxygen, ${ }^{18-21}$ ammonia $^{22}$ or polymer-forming plasmas ${ }^{2.3}$ have been used. Plasma treatments containing oxygen resulted in improved flexural properties, ${ }^{15,17,19}$ pull-out strength $^{16.20,22-24}$ and ILSS values up to 30 to $34 \mathrm{MPa} .{ }^{15-17,21}$ Improvements in bond strength were attributed to enhanced wettability, mechanical interlocking and chemical bonding. The effect of plasma treatments on the reduction in tensile strength was generally fairly small (less than $10 \%$ ). ${ }^{15,17,23,24}$ Besides corona and plasma treatments, also chemical etching has been used. ${ }^{24,25}$ Recently, Mercx et al. ${ }^{26-28}$ showed that regardless of the type of treatment, being either chemical etching, corona or plasma, the introduction

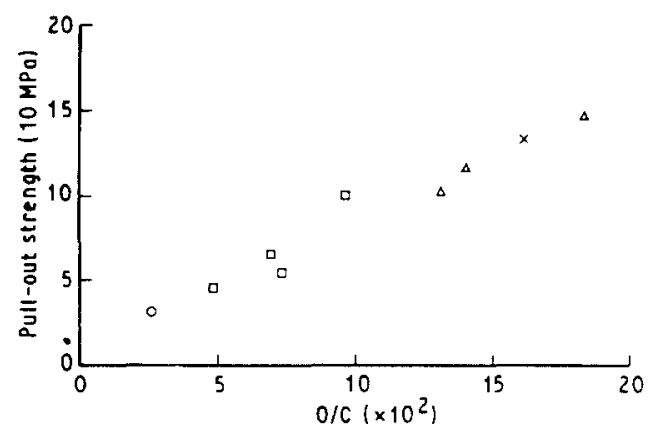

Fig. 1. Pull-out strength as a function of $\mathrm{O} / \mathrm{C}$ ratio: $\mathrm{O}$, untreated; $\square$, chlorosulphonic acid $(0-30 \mathrm{~min}) ; \triangle$, chromic acid $(0-5 \mathrm{~min}) ; x, \mathrm{KMnO}_{4} / \mathrm{H}_{2} \mathrm{O} / \mathrm{H}_{2} \mathrm{SO}_{4}(0-0.5 \mathrm{~min})$. ( $\mathrm{Re}-$ produced with permission from Mercx et al. $\left.{ }^{26}\right)$ of functional groups, rather than wettability and mechanical interlocking, is the predominant factor in improving the adhesion between ultradrawn PE and epoxy matrices. By monitoring the changes in surface topography using scanning electron microscopy (SEM) and surface composition (X-ray photoelectron spectroscopy) the improvement in pull-out strength could be related to the introduction of functional oxygen-containing groups, i.e. hydroxyl, carbonyl and carboxyl (Fig. 1).

Thus, it can be concluded that a wide range of oxidizing surface treatments is effective in raising the bond strength between HP-PE fibres and epoxy resins. However, as tested by ILSS, the composite shear strength could only be increased to maximum values of 30 to $34 \mathrm{MPa}$. Despite the significant improvement compared to composites incorporating untreated fibres, these ILSS values are still rather low when compared with those generally obtained for other advanced composite systems based on aramid, carbon and glass fibres with typical values of 55, 100 and $80 \mathrm{MPa}$, respectively. The value of 30 to $34 \mathrm{MPa}$ for HP-PE composites proved to be the 'upper' limit and is inherently related to the 1-D highly anisotropic character of ultradrawn PE fibres.

\subsection{Fibre anisotropy}

Fibre anisotropy exists in all high-performance organic fibres. Aramids possess a radial arrangement of hydrogen bonded sheets of poly ( $p$-phenylene terephthalamide) (PPTA) molecules ${ }^{29.30}$ resulting in a 1-D or in comparison with HP-PE fibres a ' $1 \frac{1}{2}-\mathrm{D}$ ' structure due to the stronger hydrogen bonds between the polymer chains in comparison with the weak Van der Waals interactions in PE. Graphite possesses a highly anisotropic sheet-like structure, ${ }^{31}$ with strong covalent bonding between hexagonally arranged carbon atoms within the layer-planes, but much weaker bonding between them. ${ }^{32}$ Consequently carbon or graphite fibres can be considered as two-dimensional (2-D) structures. On the other hand, glass fibres are typically isotropic three-dimensional (3-D) materials.

In contrast to the amount of research devoted to the improvement of fibre/matrix adhesion in order to improve the structural applicability of composites based on HP-PE fibres, only few studies were undertaken to investigate the role of fibre anisotropy on the performance of such composites. Important in this respect are the experimental difficulties in testing single fibres with a diameter of only 10 to $20 \mu \mathrm{m}$ in the lateral direction. Torsion tests have been used for the testing of a variety of fibres and permitted the measurement of the shear modulus. Typical values for shear moduli of high performance fibres such as PAN-based high strength carbon fibre (T 300), pitch-based high modulus carbon fibre (GY 70), aramid fibre (Kevlar ${ }^{\mathrm{TM}} 49$ ) and PE fibre (Spectra ${ }^{\mathrm{TM}}$ 
900) are $12,3,2 \cdot 5$ and $1 \mathrm{GPa}$ respectively. ${ }^{33,34}$ The dependence of the compressive strength of fibres on their shear modulus was noted by Norita $e t$ al. ${ }^{34}$ and Allen $e t a^{35}$ The transverse strength of fibres has been investigated using a compression test where a fibre is subjected to compressive loading across the diameter. ${ }^{33.36,37}$ Upon loading, the fibre will experience tensile stresses along the diameter in a direction normal to the direction of loading. However, determination of a value for the transverse or splitting stress is limited to brittle fibres only. ${ }^{37} \mathrm{~A}$ test method for highly anisotropic polymeric fibres has been developed by McGarry and Moalli. ${ }^{38}$ They developed a test method in which an opening mode crack is propagating axially. The initiation force provides a measure of the lateral integrity of polymeric fibres. Unfortunately, however, this test gives only indirect information on the transverse strength of such fibres.

To illustrate the highly anisotropic character of chain-extended PE, we will briefly address the mechanical properties of single crystals, i.e. the extreme case of a perfect fibre.

The most general linear relationship that connects stress and strain for an orthotropic elastic material is known as the generalized Hooke's law:

$$
\sigma_{i}=C_{i j} \varepsilon_{j} \quad i, j=1, \ldots, 6
$$

where $\sigma_{i}$ is the stress component, $C_{i j}$ is the stiffness matrix, and $\varepsilon_{j}$ are the engineering strain constants. The stress/strain relation given by eqn (1) can be expressed in the inverted form as

$$
\varepsilon_{i}=S_{i j} \sigma_{j} \quad i, j=1, \ldots, 6
$$

where $S_{i j}$ is known as the compliance matrix.

The stiffness and compliance matrix of a hypothetically perfect $\mathrm{PE}$ crystal as calculated by Tashiro et al. ${ }^{39}$ show that the compliance in the chain direction $\left(S_{33}\right)$ of such a PE crystal is orders of magnitude lower than the transverse or shear compliances of the crystal:

$$
\begin{gathered}
C_{i j}=\left|\begin{array}{llllll}
7 \cdot 99 & 3 \cdot 28 & 1 \cdot 13 & 0 & 0 & 0 \\
3 \cdot 28 & 9.92 & 2 \cdot 14 & 0 & 0 & 0 \\
1 \cdot 13 & 2 \cdot 14 & 316 & 0 & 0 & 0 \\
0 & 0 & 0 & 3 \cdot 19 & 0 & 0 \\
0 & 0 & 0 & 0 & 1 \cdot 62 & 0 \\
0 & 0 & 0 & 0 & 0 & 3 \cdot 62
\end{array}\right| \\
S_{i j}=\left|\begin{array}{lllllll}
14 \cdot 5 & -4 \cdot 78 & -0.019 & 0 & 0 & 0 \\
-4 \cdot 78 & 11 \cdot 7 & -0.062 & 0 & 0 & 0 \\
-0.019 & -0 \cdot 062 & 0 \cdot 31 & 0 & 0 & 0 \\
0 & 0 & 0 & 31 \cdot 4 & 0 & 0 \\
0 & 0 & 0 & 0 & 61 \cdot 7 & 0 \\
0 & 0 & 0 & 0 & 0 & 27 \cdot 6
\end{array}\right| \\
\left(\times 10^{-2}\right)\left(\mathrm{GPa}^{-1}\right)
\end{gathered}
$$

The influence of intermolecular forces in the crystal lattice on the anisotropy of the crystal moduli has also been studied by Nakamae and Nishino. ${ }^{40}$ They measured the crystal moduli of PE using an X-ray diffraction technique. Measured values for the longitudinal and transverse crystal moduli of PE were 235 and $4 \mathrm{GPa}$, respectively. It was shown that this anisotropic character of PE crystals becomes even more pronounced at elevated temperatures. ${ }^{41}$

The stiffness and compliance matrices for an orthotropic material like PE single crystals can be easily transferred to arbitrary coordinate axes. The compliance in load direction of an orthotropic material with its principal material axes oriented at an angle $\theta$ with the reference coordinate axes can be expressed as

$$
\begin{aligned}
\bar{S}_{33}= & S_{11} \sin ^{4} \theta+S_{33} \cos ^{4} \theta+\left(2 S_{13}+S_{56}\right) \sin ^{2} \theta \cos ^{2} \theta \\
& -2 S_{35} \cos ^{3} \theta \sin \theta-S_{15} \cos \theta \sin ^{3} \theta
\end{aligned}
$$

The off-axis modulus $E_{\theta}$ can be derived by

$$
E_{\theta}=1 / \bar{S}_{33}
$$

By plotting the modulus of a PE single crystal as a function of orientation $\theta$ a good interpretation of the highly anisotropic character of oriented PE is obtained $^{42}$ (Fig. 2). The dramatic drop in modulus, even at small angles with the chain direction, is mainly caused by the low shear modulus. For comparison, the orientation dependence of single-crystal graphite and PPTA structures is also plotted, using data from Refs 32 and 30 , respectively. Focusing on the transverse modulus, it should be noted that in plots like these,

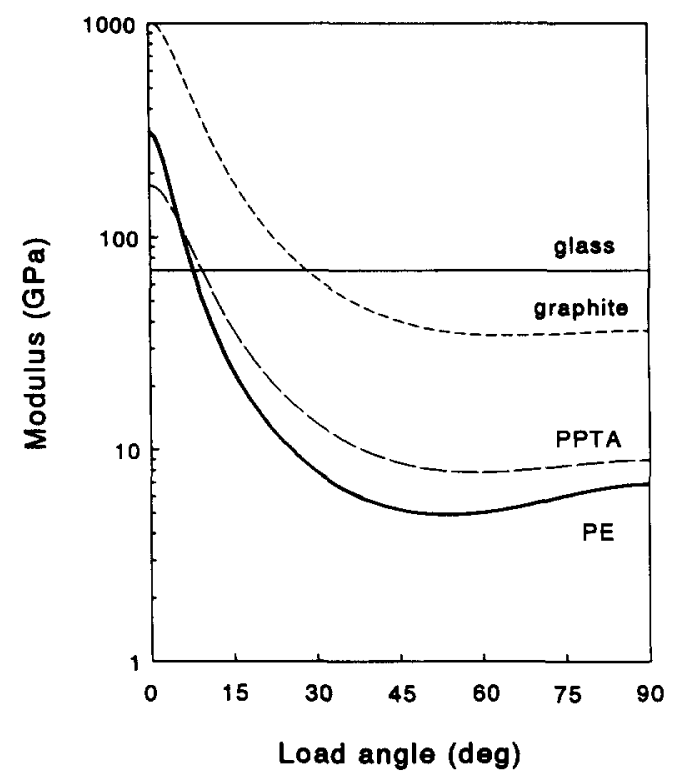

Fig. 2. Theoretical moduli of various fibres as a function of load angle. 
'fibres' rank in order of their anisotropic character, viz. with increasing transverse stiffness we have the ' $1-D$ ' PE fibre, the ' $1 \frac{1}{2}-D$ ' aramid fibre, the ' $2-D$ ' carbon fibre and finally the ' 3 -D' glass fibre.

The objective of the present study is to investigate the role of this highly anisotropic character of HP-PE fibres on the off-axis performance of their composites. To determine ultimate properties, composites incorporating untreated and plasma-treated fibres are evaluated.

\section{EXPERIMENTAL}

\subsection{Materials}

\subsubsection{Composites}

In this study we used a HP-PE fibre (Spectra ${ }^{\mathrm{TM}} 1000$ ) from Allied Signal. The matrix used was an epoxy system of Ciba Geigy based on bisphenol $\mathrm{A}$ and an anhydride curing agent (Araldite ${ }^{\mathrm{TM}}$ LY556/HY917/ DY070). To study the effect of improved adhesion on mechanical properties, composites incorporating untreated and plasma-treated fibres were manufactured. Unidirectional (UD) laminates for off-axis testing up to angles of $90^{\circ}$ were fabricated by wet-winding of fibres on a frame (Fig. 3). After winding, the impregnated fibres are degassed in a vacuum oven to obtain a void-free composite. Laminates were prepared by positioning the frame in an open-ended mould and placing the whole assembly in a hot-press. The laminate thickness and fibre volume fraction were controlled by metal stops of the required thickness, while during hot-pressing excess of resin was squeezed out through the open ends of the mould. During curing at $80^{\circ} \mathrm{C}$ for $4 \mathrm{~h}$, a pressure of 4 bar was maintained. After curing, the mould was removed and the laminates were postcured for $12 \mathrm{~h}$ at $110^{\circ} \mathrm{C}$. This manufacturing procedure resulted in nearly void-free, high quality flat laminates of 160 by $30 \mathrm{~mm}$ with a fibre volume fraction of 0.50 .

Cross-ply laminates were manufactured from UD prepregs which were prepared on a drum-winder. After winding the prepreg was B-staged in an oven. This prepreg was then used to make laminates, which were cured in a vacuum bag in combination with a hot press.
Test specimens were cut from the laminate plates using a diamond cutting wheel. Tensile specimen dimensions of all tested composites were in accordance with ASTM D-3039 standard and were provided with adhesively bonded, tapered aluminium tabs. Tensile specimens up to $10^{\circ}$ off-axis had a thickness of $1 \mathrm{~mm}$ and a width of $12 \mathrm{~mm}$ and aluminium tabs were of $50 \mathrm{~mm}$ length. Except for the $0^{\circ}$ specimen, which had a thickness of only $0.4 \mathrm{~mm}$, and aluminium tabs of $70 \mathrm{~mm}$ to prevent slip-out of the specimen, all other tensile specimens $\left(15^{\circ}, 30^{\circ}, 45^{\circ}\right.$, $60^{\circ}$ and $90^{\circ}$ off-axis and $\pm 45^{\circ}$ ) had a width of $25 \mathrm{~mm}$ and a thickness of $2 \mathrm{~mm}$.

To eliminate edge effects as a result of cutting specimens from the flat laminates, filament wound tubes also were made for transverse tensile strength evaluation. Hoop-wound tubes with a length of $300 \mathrm{~mm}$ and an inner diameter of $25 \mathrm{~mm}$ were fabricated by wet-winding of HP-PE fibres on a collapsible mandrel. The wall thickness was $2 \mathrm{~mm}$; $100 \mathrm{~mm}$ long specimens were cut from these tubes and provided with adhesively bonded tapered aluminium end reinforcements for clamping, which resulted in a $50 \mathrm{~mm}$ long test section.

\subsubsection{Fibres}

Fibre properties were evaluated for two types of specimens: (i) single filaments, and (ii) impregnated strands. To enhance handling, single filaments were adhesively bonded in a cardboard frame. This frame was clamped in the tensile machine and, prior to testing, the frame was cut, leaving a free test length of $100 \mathrm{~mm}$. Impregnated strands were manufactured by impregnating multifilament yarn in a bath of epoxy resin and winding them on a frame, with a pitch of about $10 \mathrm{~mm}$, using a filament winder. After curing, the impregnated strands, with a fibre volume fraction of 0.50 and a length of $250 \mathrm{~mm}$, were cut from the frame and provided with cardboard tabs.

\subsubsection{UHMW-PE tapes}

Apart from the production of fibres, based on the ultradrawability of solution-crystallized ultrahigh molecular weight polyethylene (UHMW-PE) (gel spin-
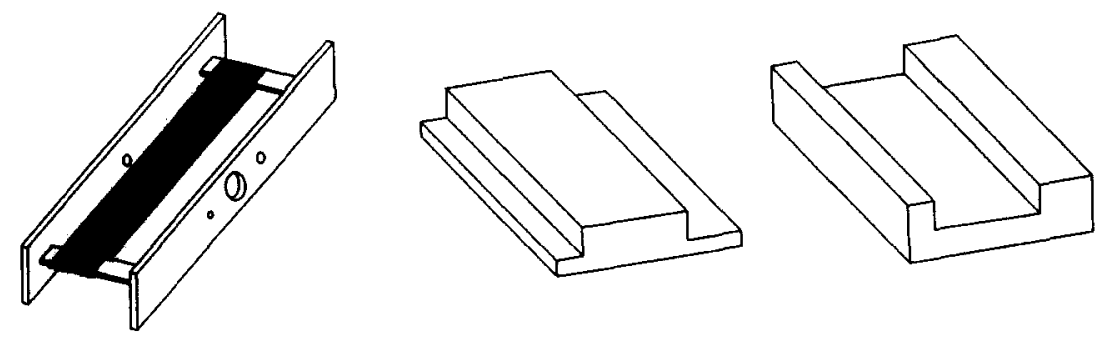

Fig. 3. Winding frame and open-ended mould for manufacture of UD composites. 
ning) it is also possible to make other structures such as tapes. ${ }^{43}$ In view of experimental difficulties with respect to off-axis testing of single fibres with a diameter of $25 \mu \mathrm{m}$, such ultradrawn tapes of UHMW-PE were prepared at DSM Research BV and used as an alternative for HP-PE fibres to investigate the off-axis strength of oriented PE structures. Solution-crystallized UHMW-PE gels were prepared by continuously extruding a $15 \%$ solution of UHMW-PE (Himont HB 312, $\boldsymbol{M}_{\mathrm{w}}=1.5 \times$ $10^{3} \mathrm{~kg} \mathrm{~mol}^{-1}$ ) in decalin. The solution was quenched in water, and the resulting gel film was dried at ambient temperatures. The gel films were subsequently uniaxially stretched at a temperature of $110^{\circ} \mathrm{C}$ to a draw ratio of 20 . Samples had a thickness of $300 \mu \mathrm{m}$ and a width of $30 \mathrm{~mm}$. Test samples were cut from these tapes under various angles ranging from $0^{\circ}$ to $90^{\circ}$ and were provided with adhesively bonded cardboard tabs.

\subsection{Testing}

\subsubsection{Tension}

Off-axis tensile tests for both ultradrawn UHMW-PE tapes and HP-PE fibre-reinforced composites as well as tensile tests on fibres were performed on a Frank 81565 universal testing machine. Except for the tensile experiments on single filaments, in all cases an extensometer was used to measure the strain in the load direction. Each specimen was loaded monotonically to fracture at a strain rate of $0.01 \mathrm{~min}^{-1}$. A minimum of five specimens was tested for each case.

During tensile testing of $0^{\circ}$ and $90^{\circ}$ composite laminates, acoustic emission ( $\mathrm{AE}$ ) was used for real-time monitoring of damage initiation and development. Acoustic emission was monitored with a piezoelectrical transducer of Physical Acoustic Corp. (PAC R 15) coupled with the specimen using vacuum grease. A PAC 8900 Locan AT system was used, which allows us to analyse the AE event with respect to different characteristic parameters such as counts, peak amplitude, duration, rise time and energy. The AE system also included a $40 \mathrm{~dB}$ preamplifier (PAC 1200 A). Nominal instrument settings were a threshold of $25 \mathrm{~dB}$ and a preamplifier gain of $40 \mathrm{~dB}$.

\subsubsection{Compression}

Off-axis compressive tests were conducted at a test speed of $0.5 \mathrm{~mm} \mathrm{~min}^{-1}$. Test specimens were in accordance with ASTM D-3410 with the exception that the Celanese type of test fixture also allowed for specimen widths other than the standard $6 \mathrm{~mm}$. Specimens had a thickness of $4 \mathrm{~mm}$, a width of $20 \mathrm{~mm}$ and a free test length between the tabs of $12 \mathrm{~mm}$.
Load introduction was provided by aluminium end-tabs.

\section{MACROMECHANICS}

\subsection{Off-axis stifiness}

Similar arguments as used for the single crystals in Section 1.2 can be applied to UD composites and, based on micromechanics, ${ }^{44}$ it can be expected that the anisotropic character of the HP-PE fibre results in highly anisotropic composites on a macroscopic level.

The off-axis compliance of an orthotropic lamina under in-plane stresses in the principal directions $(1,2)$ can be determined using the transformation equation: ${ }^{45,46}$

$$
\begin{aligned}
\bar{S}_{11}= & S_{11} \cos ^{4} \theta+\left(2 S_{12}+S_{66}\right) \\
& \times \sin ^{2} \theta \cos ^{2} \theta+S_{22} \sin ^{4} \theta
\end{aligned}
$$

where $\bar{S}_{11}$ is the compliance in the load direction, and $\theta$ is the angle between the load and fibre direction and in which the compliance components are related to the engineering constants by

$$
\begin{gathered}
S_{11}=\frac{1}{E_{11}} ; \quad S_{22}=\frac{1}{E_{22}} \\
S_{12}=-\frac{v_{12}}{E_{11}}=-\frac{v_{21}}{E_{22}} ; \quad S_{66}=\frac{1}{G_{12}}
\end{gathered}
$$

where $E_{11}$ is the longitudinal Young's modulus, $E_{22}$ is the transverse Young's modulus, $G_{12}$ is the longitudinal-transverse shear modulus, $v_{12}$ is the longitudinal (or major) Poisson's ratio, and $v_{21}$ is the transverse (or minor) Poisson's ratio.

The off-axis stiffness of an orthotropic lamina, with its principal material axis oriented at an angle $\theta$ with the reference coordinate axis, yields:

$$
\frac{1}{E_{\theta}}=\frac{\cos ^{4} \theta}{E_{11}}+\left(\frac{1}{G_{12}}-\frac{2 v_{12}}{E_{11}}\right) \sin ^{2} \theta \cos ^{2} \theta+\frac{\sin ^{4} \theta}{E_{22}}
$$

Table 1 gives the engineering constants for HPPE/epoxy composites as calculated with eqn (7) from the measured off-axis stiffness data using a major Poisson's ratio of $0 \cdot 32 .{ }^{47}$

Figure 4 plots the measured and calculated off-axis stiffness of undirectional HP-PE/epoxy composites. No influence of improved adhesion after plasma treatment on the moduli of the composite laminates was observed. For comparison, we also plotted the

Table 1. Engineering constants for HPPE/epoxy composites

\begin{tabular}{cccc}
\hline $\begin{array}{c}E_{11} \\
(\mathrm{GPa})\end{array}$ & $\begin{array}{c}E_{22} \\
(\mathrm{GPa})\end{array}$ & $\begin{array}{c}G_{12} \\
(\mathrm{GPa})\end{array}$ & $v_{12}$ \\
\hline 40 & $2 \cdot 7$ & $1 \cdot 1$ & 0.32 \\
\hline
\end{tabular}




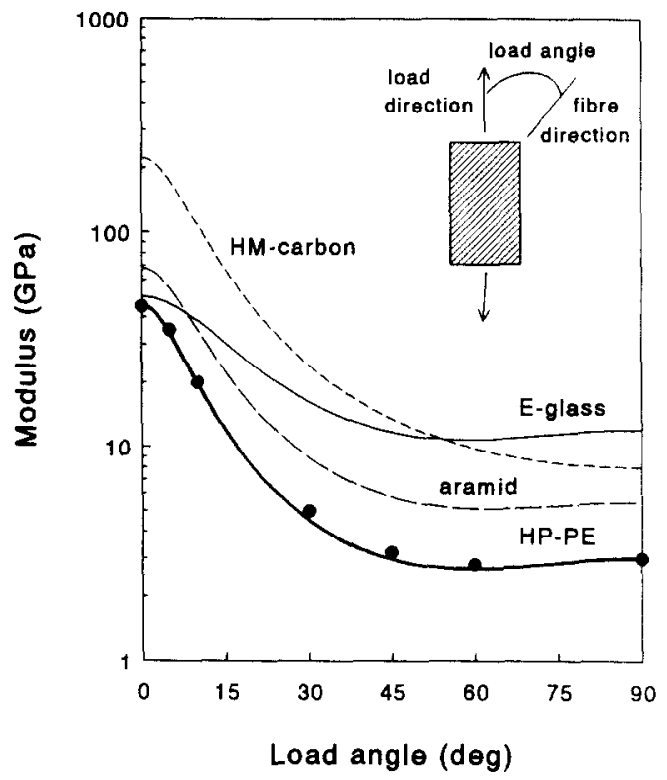

Fig. 4. Off-axis stiffness of HP-PE/epoxy composites ( $\bullet$, measurement; - , prediction using eqn (7)) in comparison with the off-axis stiffness of composites based on E-glass, HM-carbon and aramid fibre.

uff-axis stiffness of other composite systems based on E-glass, HM-carbon and aramid fibre using engineering constants taken from Ref. 46. By comparing the off-axis stiffness of the composites with the orientation dependence of the theoretical moduli of the various fibres (Fig. 2) we see that for both fibres and composites the same trend is observed. The lowest transverse modulus is observed for the HP-PE/epoxy composite and the highest transverse modulus for the E-glass/epoxy composite.

\subsection{Off-axis strength}

There are a number of theories for the prediction of the strength of composite materials subjected to a combined stress state. In this section we will interpret strength using failure criteria. There are several failure criteria for UD composites. They are all based on the (experimentally obtained) on-axis stress or strain as the basic variable with different tensile and compressive strengths. An often used approach for failure criteria of UD composites is the maximum stress criterion: ${ }^{45,46}$

$$
\sigma_{11} \leq X \quad \text { or } X^{\prime \prime} ; \quad \sigma_{22} \leq Y \quad \text { or } \quad Y^{\prime} ; \quad \tau_{12} \leq S
$$

where $\sigma_{11}, \sigma_{22}$ and $\tau_{12}$ are the longitudinal, transverse and shear stress, respectively, $X$ is the longitudinal tensile strength, $X^{\prime}$ is the longitudinal compressive strength, $Y$ is the transverse tensile strength, $Y^{\prime}$ is the transverse compressive strength, and $S$ is the in-plane shear strength. Failure occurs when one of the inequalities is met. It is assumed that each stress component has its own criterion and is not affected by the other components. In off-axis situations we can express the off-axis strength in terms of on-axis strength, which yields:

$$
\begin{gathered}
\sigma_{\theta}=\frac{X}{\cos ^{2} \theta} \\
\sigma_{\theta}=\frac{Y}{\sin ^{2} \theta} \\
\sigma_{\theta}=\frac{S}{\sin \theta \cos \theta}
\end{gathered}
$$

A maximum work criterion was derived by $\mathrm{Tsai}^{46}$ from a yield criterion for anisotropic materials by Hill and is, therefore, often referred to as the Tsai-Hill theory. In contrast to the maximum stress theory, this criterion provides an interaction between different failure modes and is analogous to that of Von Mises for isotropic materials. Failure is initiated when the following inequality is met:

$$
\left(\frac{\sigma_{11}}{X}\right)^{2}-\frac{\sigma_{11} \sigma_{22}}{X^{2}}+\left(\frac{\sigma_{22}}{Y}\right)^{2}+\left(\frac{\tau_{12}}{S}\right)^{2} \leq 1
$$

In an off-axis situation the failure criterion yields:

$$
\begin{aligned}
\left(\frac{\cos ^{4} \theta}{X^{2}}\right)-\left(\frac{\cos ^{2} \theta \sin ^{2} \theta}{X^{2}}\right) & +\left(\frac{\sin ^{4} \theta}{Y^{2}}\right) \\
& +\left(\frac{\sin ^{2} \theta \cos ^{2} \theta}{S^{2}}\right) \leq \frac{1}{\sigma_{\theta}^{2}}
\end{aligned}
$$

Table 2 gives the longitudinal, transverse and shear strength of HP-PE/epoxy and plasma treated HP-PE/epoxy composites. The longitudinal ( $X$ and $\left.X^{\prime}\right)$ and transverse $\left(Y\right.$ and $\left.Y^{\prime}\right)$ strengths are taken directly from the $0^{\circ}$ and $90^{\circ}$ tensile and compression tests on UD composites. The in-plane shear strength $(S)$ was determined from the $5^{\circ}$ off-axis tension specimen and calculated using eqn (11). The experimental accuracy of all quoted data is within $10 \%$.

Figure 5 gives a comparison of the measured values of tensile strengths and the predicted off-axis tensile strength using the Tsai-Hill criterion. As expected, for surface treated HP-PE fibres an increase in off-axis strength is found because of improved interface dominated properties such as shear and transverse strength of the composite. Furthermore, it is shown that the Tsai-Hill predictions are in excellent agreement with the experimental tensile strength data for both types of composites.

In contrast to the high level of anisotropy in HP-PE composites when loaded in tension, in compression only a relatively small influence of fibre orientation on compressive strength of HP-PE composites is 
Table 2. Strengths of unidirectional HP-PE/epoxy composites $\left(V_{\mathrm{f}}=50 \%\right)$

\begin{tabular}{lcc}
\hline & Untreated HP-PE & Plasma-treated HP-PE \\
\hline $\begin{array}{l}\text { Longitudinal } \\
\text { tensile strength (MPa) }\end{array}$ & 910 & 1070 \\
$\begin{array}{l}\text { Transverse } \\
\text { tensile strength (MPa) }\end{array}$ & $2 \cdot 5$ & 8 \\
$\begin{array}{l}\text { Londitudinal } \\
\text { compressive strength (MPa) }\end{array}$ & 73 & 91 \\
$\begin{array}{l}\text { Transverse } \\
\text { compressive strength (MPa) }\end{array}$ & 21 & 44 \\
$\begin{array}{l}\text { In-plane } \\
\text { shear strength (MPa) }\end{array}$ & 6 & 17 \\
\hline
\end{tabular}

observed (Fig. 6). Generally, in compression the off-axis strength changes also from a fibre dominated property to a matrix dominated property. However, due to the low on-axis compressive strength of both untreated and treated HP-PE/epoxy composites, which is even lower than that of pure epoxy $(120 \mathrm{MPa})$, the compressive strength of this composite system is always dominated by the epoxy matrix.

\subsubsection{Influence of fibre anisotropy on off-axis strength of composites}

In this section we will discuss the off-axis strength of HP-PE composites in relation to the off-axis strength of oriented PE structures. More quantitative information on the role of fibre anisotropy on the (off-axis) strength of HP-PE composites would be attained if off-axis fibre data were available. As an alternative to off-axis fibre testing, ultra-drawn UHMW-PE tapes

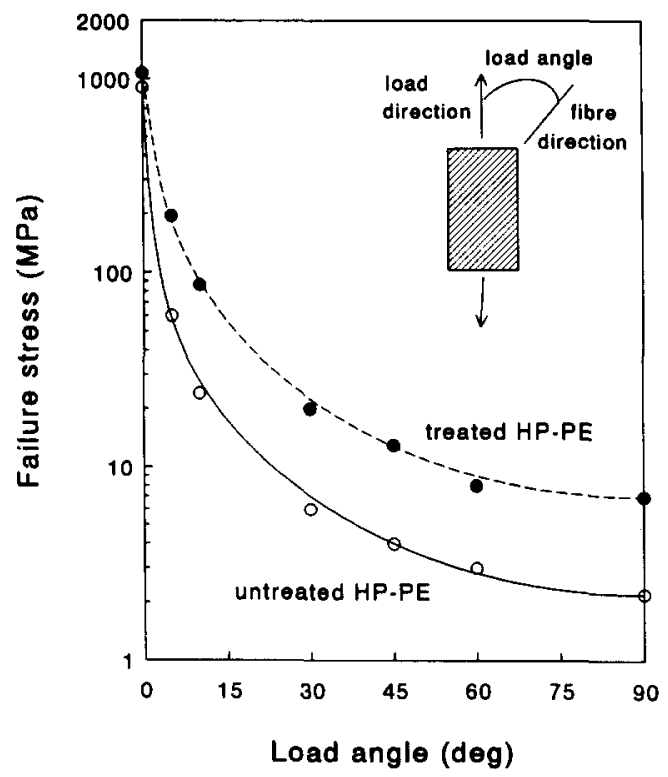

Fig. 5. Off-axis tensile strength of HP-PE/epoxy and plasma-treated HP-PE/epoxy composites. Lines are TsaiHill predictions. were used to investigate the off-axis strength of oriented PE structures. Figure 7 shows the off-axis tensile strength of both ultradrawn UHMW-PE tapes and plasma-treated HP-PE/epoxy composites.

Table 3 gives the transverse and shear properties as obtained from the off-axis tests on ultradrawn UHMW-PE tape. From these data it can already be concluded that, in the case of perfect adhesion and assuming a 'strength-of-materials' model, the transverse and shear strength of the composites is limited by the strength of the fibre, since transverse and shear strength values of UHMW-PE tape are significantly lower than those of the epoxy matrix (90 and $60 \mathrm{MPa}$, respectively).

\section{FAILURE MODES AND MICROMECHANICS}

In this section the influence of fibre/matrix adhesion and fibre anisotropy on the failure modes of HP-PE/epoxy composites will be discussed. Furthermore, some attempts will be made to quantify the role

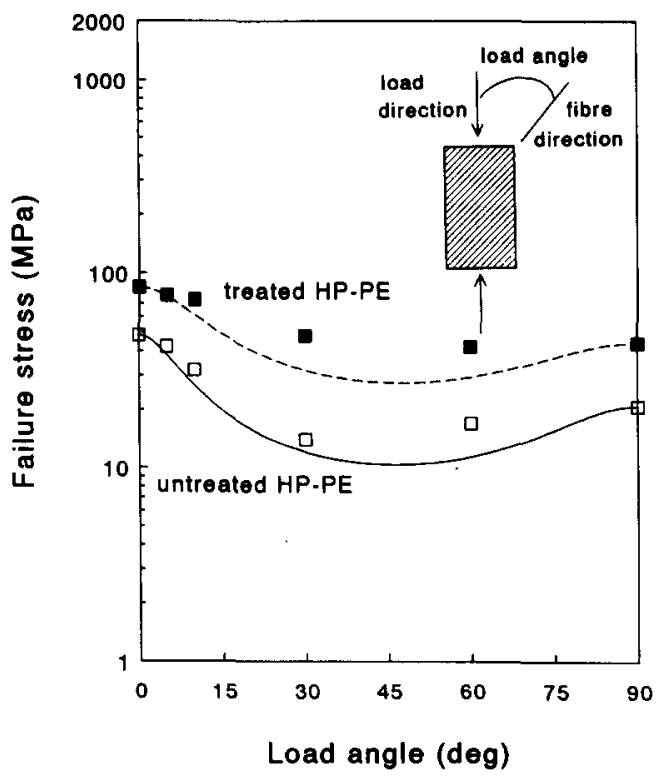

Fig. 6. Off-axis compressive strength of UD composites with Tsai-Hill predictions. 


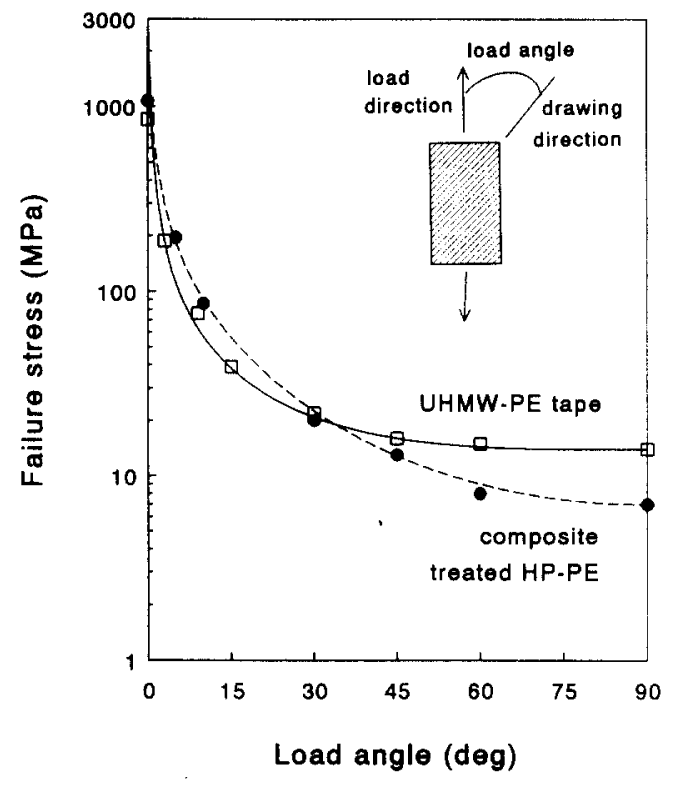

Fig. 7. Off-axis strength of ultradrawn UHMW-PE tapes and plasma-treated HP-PE composites. Drawn lines are Tsai-Hill predictions.

of fibre anisotropy in ultimate properties of HP-PE composites, using micromechanics.

\subsection{Regions of single failure modes}

Regions where single failure modes predominate can be identified by plotting the normalized fracture stresses of the composites as a function of load angle $\theta$. Fracture stresses are normalized with respect to their uniaxial strengths; $\sigma_{11} / X, \sigma_{22} / Y$ and $\tau_{12} / S$. Figure 8 shows the plot for normalized stresses of both treated and untreated HP-PE/epoxy composites; $\sigma_{11} / X, \tau_{12} / S$ and $\sigma_{22} / Y$ are closer to unity in the load-angle range $0^{\circ}<\theta<1^{\circ}, \quad 1^{\circ}<\theta<20^{\circ}$ and $20^{\circ}<\theta<90^{\circ}$, respectively. In the range $15^{\circ}<\theta<30^{\circ}$ the ratios $\tau_{12} / S$ and $\sigma_{22} / Y$ have comparable values, suggesting that in this range the failure mode is controlled by a combination of shear and transverse stresses. In the load-angle range $1^{\circ}<\theta<20^{\circ}$ and $20^{\circ}<\theta<90^{\circ}$ intralaminar shear and transverse tensile failure modes are predominant. This high anisotropy in this type of composite results in an extremely narrow load-angle range for longitudinal tension as failure mode. For composites incorporating untreated fibres the transition from longitudinal to shear failure occurs at a load angle of $0 \cdot 4^{\circ}$, whereas for plasma-treated HP-PE composites a transition in failure mode is predicted at

Table 3. Transverse and shear properties of UHMW-PE tapes

\begin{tabular}{cccc}
\hline $\begin{array}{c}E_{22} \\
(\mathrm{GPa})\end{array}$ & $\begin{array}{c}G_{12} \\
(\mathrm{GPa})\end{array}$ & $\begin{array}{c}\sigma_{22} \\
(\mathrm{MPa})\end{array}$ & $\begin{array}{c}\tau_{12} \\
(\mathrm{MPa})\end{array}$ \\
\hline 2 & $0 \cdot 8$ & 14 & 10 \\
\hline
\end{tabular}

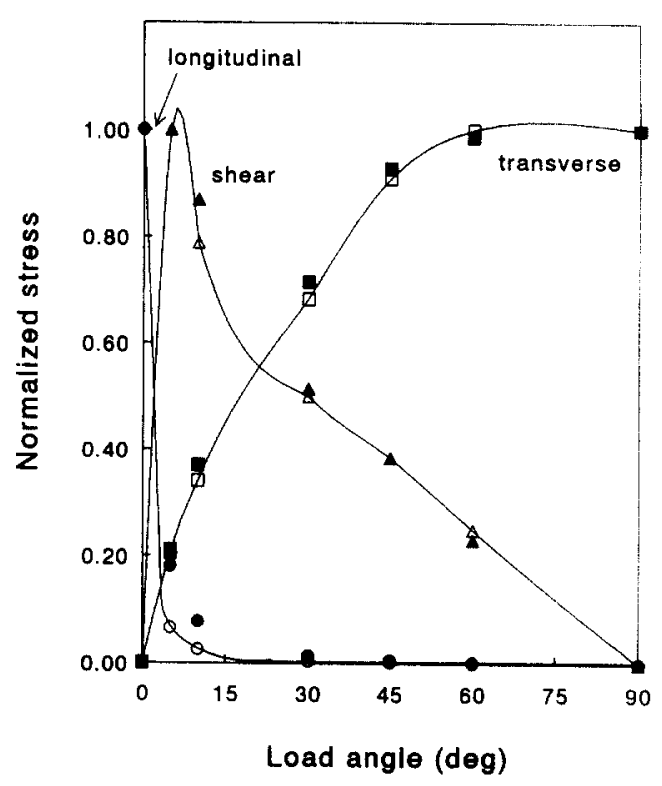

Fig. 8. Measured fracture stresses of UD HP-PE/epoxy laminates normalized with their respective uniaxial strengths.

an angle of $0.9^{\circ}$, using eqns (9) and (10). Since fibre misalignment in composite laminates can easily exceed $1^{\circ}$ it is clear that especially in untreated HP-PE composites failure of longitudinal specimens will initiate from intralaminar shear stresses. Therefore, for HP-PE/epoxy laminates even the longitudinal tensile strength can be regarded as an off-axis property.

It is also important to note that for HP-PE/epoxy composites a maximum in shear stress is observed for the $5^{\circ}$ off-axis specimen, instead of the $10^{\circ}$ off-axis specimen, which is normally used for shear strength evaluation. ${ }^{44}$ Therefore, in our case, $5^{\circ}$ off-axis data were used for the calculation of the in-plane $(1,2)$ shear strength as listed in Table 2.

\subsection{Longitudinal tensile strength}

\subsubsection{Influence of adhesion on fibre efficiency}

From the data given in Table 2 we see an increase in the longitudinal tensile strength of $18 \%$ for composites incorporating plasma-treated fibres. Since plasma treatment results in a reduction of about $10 \%$ in tensile strength of HP-PE fibres, ${ }^{15,17,23,24}$ it can be concluded that plasma-treated fibres are more effective as a reinforcing element for composites based on epoxy resins. The tensile strengths of HP-PE fibres are listed in Table 4.

Based on a rule of mixture (ROM) relationship for the tensile strength of fibre-reinforced composites, including a parameter $k$, the influence of plasma treatment on the fibre efficiency can be demonstrated:

$$
\sigma_{11}=k\left[\sigma_{\mathrm{f}} V_{\mathrm{f}}+E_{\mathrm{m}} \varepsilon_{\mathrm{f}}\left(1-V_{\mathrm{f}}\right)\right]
$$


Table 4. Tensile strengths of HP-PE fibres

\begin{tabular}{lcc}
\hline & $\begin{array}{c}\text { Untreated HP-PE, } \\
\sigma_{\mathrm{f}}(\mathrm{GPa})\end{array}$ & $\begin{array}{c}\text { Plasma-treated HP-PE, } \\
\sigma_{\mathrm{f}}(\mathrm{GPa})\end{array}$ \\
\hline Single filament & 3.36 & 3.00 \\
Impregnated strand & $2 \cdot 61$ & $2 \cdot 48$ \\
\hline
\end{tabular}

where $\sigma_{11}$ is the composite tensile strength (see Table 2), $\sigma_{\mathrm{f}}$ is the fibre tensile strength, $\varepsilon_{f}$ is the failure strain of the fibre, $E_{\mathrm{m}}$ is the modulus of the matrix, and $V_{\mathrm{f}}$ is the volume fraction of fibre. Given a nominal fibre volume fraction of 0.51 , a matrix modulus of $3.4 \mathrm{GPa}$, a fibre failure strain of $3 \%$ and fibre strength values of Table 4 , the efficiency parameter $k$ can be calculated (Table 5).

After surface treatment we see an increase in fibre efficiency. The low values for $k$, based on single-fibre data, show rather poor fibre efficiency in HP-PE composites and suggest a failure process in HP-PE composites which is governed by other processes than fibre fracture, such as, for example, interface failure or matrix cracking. Impregnated strand data should give a good comparison between the strength of a HP-PE fibre in a laminate and in an impregnated strand, since in both cases the strength of the fibre is evaluated in a composite. However, even in the case of data based on impregnated strands, fibre efficiency is rather low.

Failure of the composite laminate may occur at a lower stress level due to longitudinal splitting, viz. interface failure or matrix cracking, as a result of fibre misalignment in the composite laminate, initiating shear failure even at very small angles $\left(<0.4^{\circ}\right.$ or $\left.0.9^{\circ}\right)$, as shown by Fig. 8 . This assumption is supported by the macroscopic failure modes of the two types of HP-PE composites, which showed a dramatic change in the failure mode after surface treatment. Untreated HP-PE/epoxy composites failed by extensive longitudinal splitting along the whole length of the specimen, resulting in a brush-like fracture surface, whereas composites incorporating treated HP-PE failed in a more brittle mode with a distinct fracture surface and only little longitudinal splitting, which suggests more fibre dominated fracture behaviour and an increase in fibre efficiency. However, in the case of treated HP-PE fibres on a microscale fibre, pull-outs are also still evident (Fig. 9).

\subsubsection{Influence of adhesion on damage development}

In order to investigate the influence of fibre surface treatment on failure modes and progressive damage development during uniaxial loading of UD composites, AE studies were undertaken. In Fig. 10 the plot of cumultative hits versus strain is shown for both untreated and treated HP-PE composites. The AE hits (or events) observed during tensile loading of the UD composite increased in number as the test progressed. For composites incorporating untreated fibres, initial emissions occurred almost immediately upon loading, presumably due to debonding. Composites incorporating treated fibres showed an onset of emissions, starting at $12 \%$ of maximum load, with a rapid increase at $30 \%$ of maximum load. However, in untreated fibre composites this progressive increase in number of hits, which is indicative for progressive fibre failure, is not observed. The proportional increase in hits with load in untreated fibre composites, suggests that in this type of composite less fibre failure occurs and failure mechanisms are more dominated by other failure modes, presumably being debonding and/or interlaminar shear failure.

The relationship between $A E$ amplitudes and fracture mechanisms in composites has been extensively studied. ${ }^{50}$ Amplitude distribution anslysis of $\mathrm{AE}$ signals has shown itself useful in discriminating between different fracture mechanisms in composite materials. In the initial stages of tensile testing, low amplitude emissions correspond to matrix cracking or debonding, whereas fibre fracture is generally characterized by high amplitude emissions. Figure 11 shows the distribution of the peak amplitudes for composites with treated fibres. This composite possesses a concave shaped curve with the highest amplitude counts at about $30 \mathrm{~dB}$, indicating interface or matrix failure. ${ }^{50}$ In the treated HP-PE composites a typical case of a double-peaked amplitude distribution occurs as could be expected in the normal case of fibre

Table 5. Efficiency parameter $\boldsymbol{k}$ for unidirectional HP-PE composites

\begin{tabular}{lcc}
\hline & $\begin{array}{c}\text { Untreated HP-PE } \\
(k)\end{array}$ & $\begin{array}{c}\text { Plasma-treated HP-PE } \\
(k)\end{array}$ \\
\hline Single filament & 0.52 & 0.68 \\
Impregnated strand & 0.66 & 0.81 \\
\hline
\end{tabular}




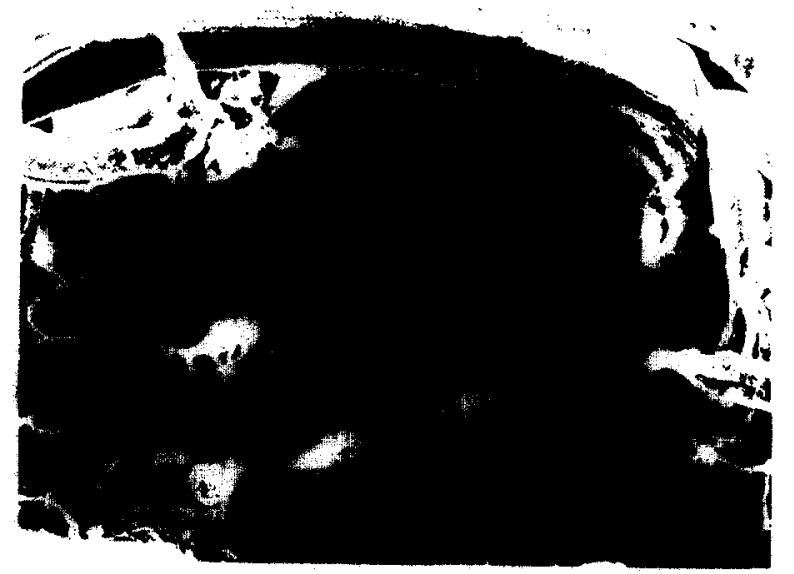

Fig. 9. SEM of a longitudinal fracture surface of treated HP-PE/epoxy composite showing fibre pull-out on a microscale.

fracture in combination with matrix cracking. High amplitude vents of $75 \mathrm{~dB}$ are present at higher loads $(>65 \%)$, which indicates that at these loads a significant amount of fibre fracture occurs. Composites with untreated HP-PE fibres showed no double peak with almost no high amplitude events in the range $70-80 \mathrm{~dB}$ and, at all load levels, amplitude distribution curves similar to that of treated HP-PE composites in the load range $0-65 \%$ (see Fig. 11).

From the AE experiments it can be concluded that upon loading, less fibre fracture occurs in the untreated HP-PE composites compared with composites with an improved level of fibre/matrix adhesion. In untreated HP-PE composites damage occurs by debonding or interface failure, resulting in extensive longitudinal splitting of the test specimen. In the case of treated fibre composites, however, more fibre fracture occurs since multiple fibre fracture takes place in a single filament because of a decrease in

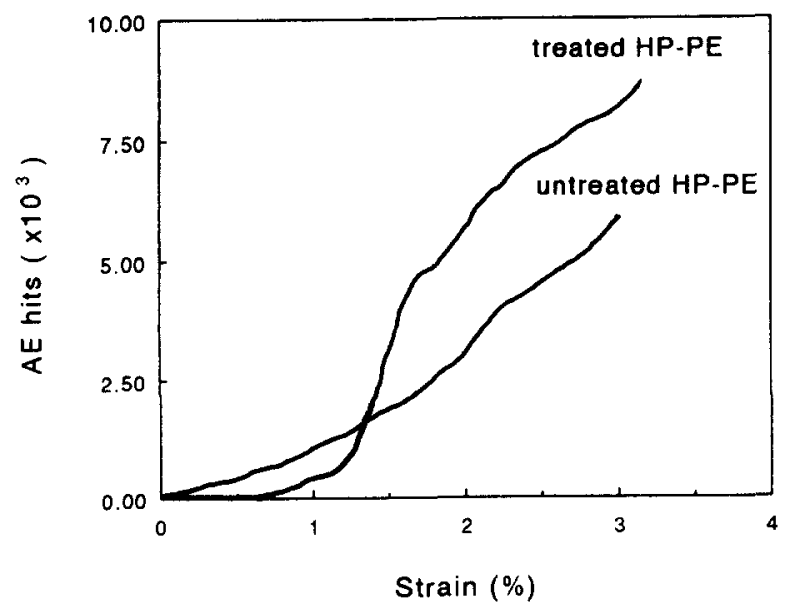

Fig. 10. Plots of cumulative hits versus strain for longitudinal tensile loading.

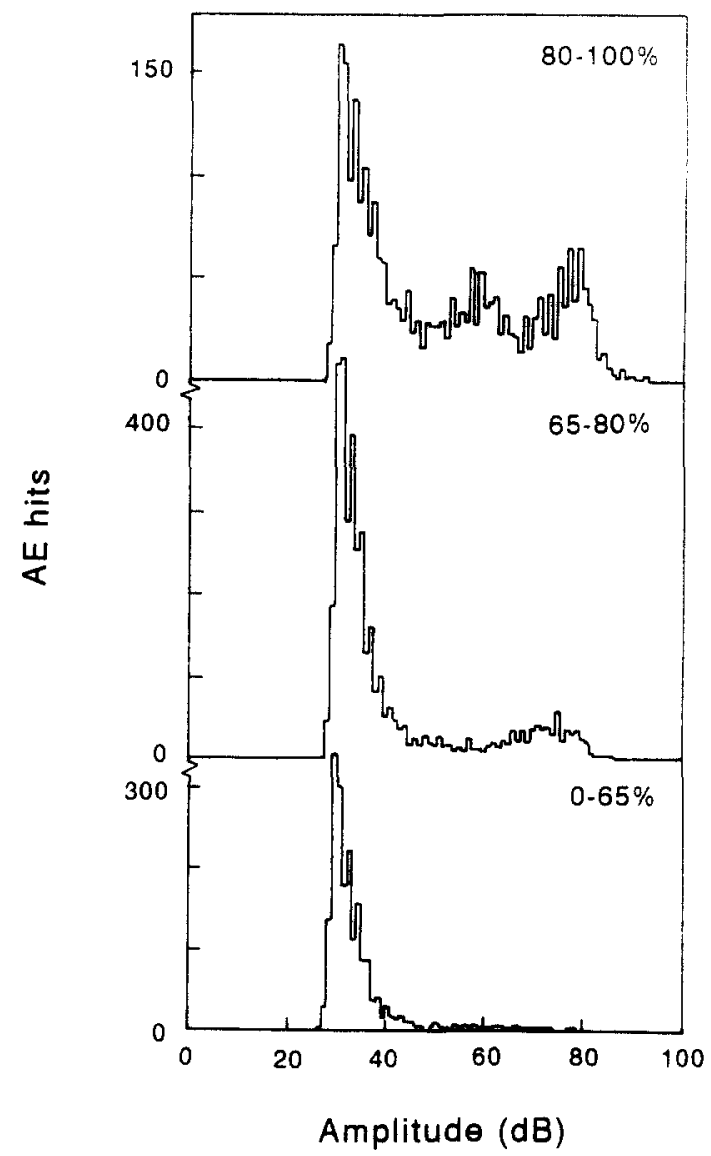

Fig. 11. Amplitude distribution of $A E$ hits of treated HP-PE/epoxy composites at different load levels.

ineffective length with improved interfacial bond strength, after an initial fibre breakage. The debonding length for untreated HP-PE fibres prevents multiple fibre fractures since no fibre fracture will occur over its ineffective length.

\subsection{Transverse tensile strength}

In this section we will investigate whether the low transverse strength of UD HP-PE/epoxy composites originates from poor adhesion or from the highly anisotropic character of HP-PE fibres.

\subsubsection{Influence of adhesion on strength and failure mode}

Two types of transverse tensile tests were performed. First, transverse tensile tests on standard UD laminated plates according to ASTM D-3039 and secondly, transverse tensile tests on UD filament wound tubes. The latter tests were conducted to eliminate edge effects as a result of cutting test specimens from the laminated plates.

As expected, an increase in transverse composite strength is observed after fibre surface treatment (Table 6). However, even in the ultimate case of a plasma-treated composite tube, the transverse strength does not exceed $10-11 \mathrm{MPa}$, which is very low 
Table 6. Transverse strengths of HP-PE/epoxy composites

\begin{tabular}{lcc}
\hline & $\begin{array}{c}\text { Untreated HP-PE, } \\
\sigma_{22}(\mathrm{MPa})\end{array}$ & $\begin{array}{c}\text { Plasma-treated HP-PE, } \\
\sigma_{22}(\mathrm{MPa})\end{array}$ \\
\hline UD laminate & $2 \cdot 5$ & $8 \cdot 5$ \\
Hoop wound tube & 4 & $10 \cdot 5$ \\
\hline
\end{tabular}

compared to that of other composites based on, e.g. glass $(50 \mathrm{MPa})$ or carbon fibres $(60 \mathrm{MPa}) .^{45,46}$ Tests on composite tubes yield values for the transverse strength that are only a little higher than those of laminated plates.

A change in failure mode from total debonding (Fig. 12(a)) to a combination of debonding with fibre splitting is observed in transverse tensile specimens (Fig. 12(b)) with surface-treated fibres, suggesting that these low values originate from the low transverse strength of the fibre rather than from a poor interfacial bond strength. Similar effects have been observed also in pull-out experiments, where after

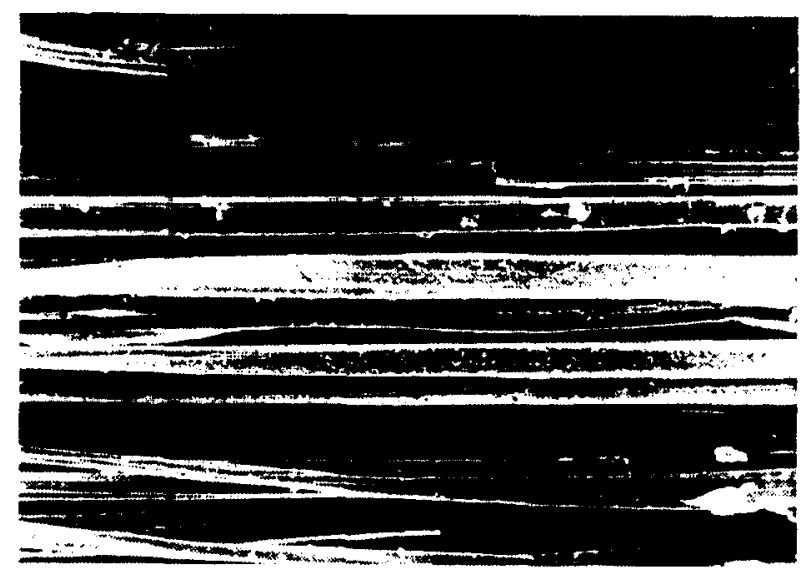

(a)

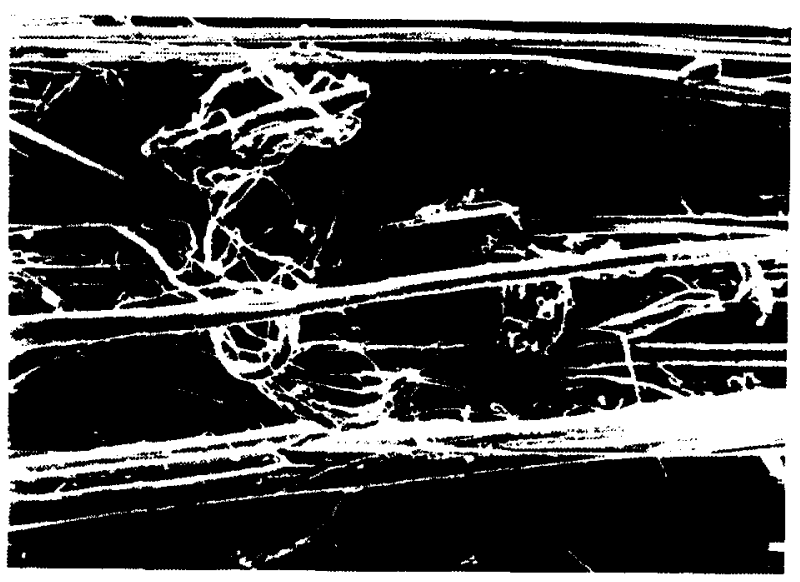

(b)

Fig. 12. SEM of transverse fracture surface of: (a) untreated HP-PE/epoxy composite showing debonding, and (b) treated HP-PE/epoxy composite showing fibre splitting and fibrillation. surface treatment the failure mode changed from debonding to rupture within the fibre..$^{7,26,28}$

\subsubsection{Influence of adhesion on damage development}

Figure 13 shows the cumulative plot of hits versus strain level for both types of composites. Fibre surface treatment results in a higher onset of damage initiation at $50 \%$ of the maximum load (or strain), whereas in untreated HP-PE composites initiation of AE occurs at $20 \%$ of the maximum load. Also the total number of $\mathrm{AE}$ events is strongly reduced, by a factor of 10 , with improved adhesion, indicating that, in the composite with the relatively good fibre-matrix bonding, failure occurs in a rather brittle manner, i.e. microcracks are localized and initiation of damage results in immediate failure of the composite. In the untreated composite, however, debonding occurs presumably throughout the whole composite, and initiation of debonding does not result in immediate failure of the laminate.

No influence of fibre surface treatments on the amplitude distribution was observed. Although fractographs showed a clear change in failure mode from debonding to fibre splitting with increasing levels of adhesion, both fracture mechanisms were characterized by low amplitude events. Since the transverse strength of HP-PE fibres in orders of magnitude lower than the longitudinal strength, fibre splitting will be accompanied with low energy events and consequently low amplitudes.

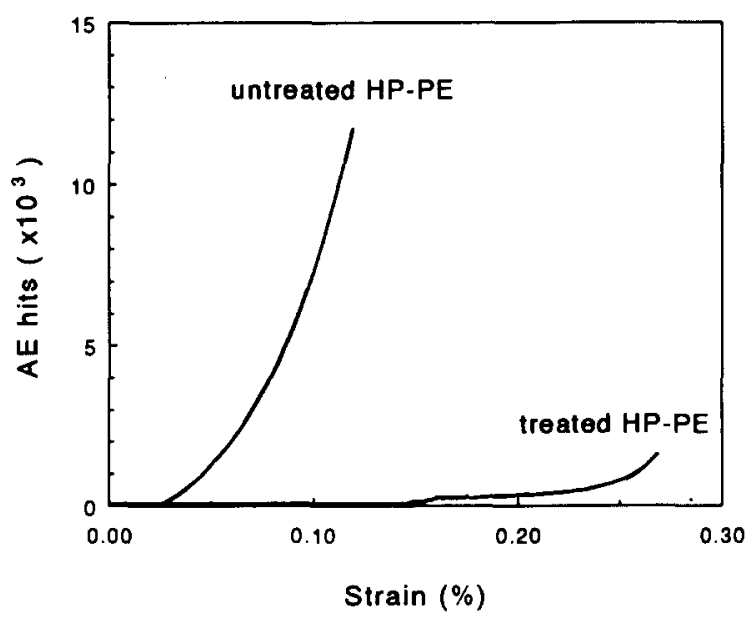

Fig. 13. Cumulative plots of hits versus strain level for uniaxially loaded transverse composite laminates incorporating untreated and treated HP-PE fibres. 


\subsubsection{Micromechanics: ultimate properties}

In this section an attempt will be made to determine the ultimate transverse strength of HP-PE composites based on its constituents. Upon transverse loading of the composite a complex state of stress is induced as a result of differences in properties of the fibre and the matrix. To account for stress concentrations on transverse composite strength a micromechanical analysis, using the finite element method (FEM), was utilized. In the present study, a 2-D generalized plane strain finite element micromechanical model of the cross-section of a UD composite is used to predict the stress situation in a composite system with fibres of lower stiffness than the matrix. A hexagonal array of elastic fibres in an elastic matrix was modelled, assuming a perfect fibre-matrix interfacial bond. Similar to the analysis of Adams and Doner, ${ }^{51}$ local states of stress are calculated. By taking a representative section of the hexagonal array of fibres, the model geometry can be reduced to a quarter of fibre in a block of matrix. The MARC ${ }^{52}$ finite element program was used. Figure 14 shows the mesh. The composite body is loaded with a normal stress in the $y$ direction.

Table 7 shows the material parameters used for fibre and matrix. Data for the HP-PE fibres were obtained from the off-axis tensile tests on UHMW-PE tapes (see Fig. 7). Major and minor Poisson ratios for the HP-PE fibres as well as thermal expansion coefficients were estimated from composite data ${ }^{47}$ using a ROM relationship.

In order to relate local states of stresses to composite strength using micromechanics, we have to take residual thermal stresses into account. Figure 15(a) and (b) shows the residual radial stresses and the maximum principle stresses in the HP-PE fibre, respectively, in an unloaded composite as calculated by FEM after cooldown from cure temperature
Table 7. Material parameters of HP-PE fibre and epoxy matrix

\begin{tabular}{lcc}
\hline & HP.PE & Epoxy \\
\hline$E_{11}(\mathrm{GPa})$ & 80 & - \\
$E_{22}(\mathrm{GPa})$ & 2 & - \\
$G_{12}(\mathrm{GPa})$ & $0 \cdot 8$ & - \\
$v_{12}$ & $0 \cdot 3$ & - \\
$v_{23}\left(\mathrm{C}^{-1}\right)\left(\times 10^{-6}\right)$ & $0 \cdot 01$ & - \\
$\alpha_{11}\left(\mathrm{C}^{\circ}\right)$ & -12 & - \\
$\alpha_{22}\left({ }^{\circ} \mathrm{C}^{-1}\right)\left(\times 10^{-6}\right)$ & 200 & - \\
$E(\mathrm{GPa})$ & - & $3 \cdot 4$ \\
$G(\mathrm{GPa})$ & - & $1 \cdot 2$ \\
$v$ & - & $0 \cdot 37$ \\
$\alpha\left({ }^{\circ} \mathrm{C}^{-1}\right)\left(\times 10^{-6}\right)$ & - & 67 \\
\hline
\end{tabular}

$\left(110^{\circ} \mathrm{C}\right)$ to room temperature $\left(20^{\circ} \mathrm{C}\right),\left(\Delta T=90^{\circ} \mathrm{C}\right)$. The radial stress distribution in the fibre, as shown in Fig. 15(a), shows relatively high stresses at the fibre/matrix interface of the order of $8 \mathrm{MPa}$. Although we cannot directly relate debonding stresses in the normal direction to interfacial shear strength values as obtained from, e.g. pull-out measurements, which are commonly used to characterize the interfacial bond strength, we may expect that debonding stresses in the normal direction are of the same order of mangitude as the interfacial shear strength. Especially in the case of composites with untreated fibres, reported pull-out values are extremely low, ${ }^{16,20,22-24,26}$ indicating the high probability of fibre/matrix debonding due to residual thermal stresses. This seems to be in accordance with AE data of untreated HP-PE composites, which showed activity immediately upon loading of both longitudinal and transverse specimens (see Section 4.2).

Figure 16 shows the stress situation in a composite after applying a load of $10 \mathrm{MPa}$ and assuming perfect adhesion. If no curing stresses are taken into account
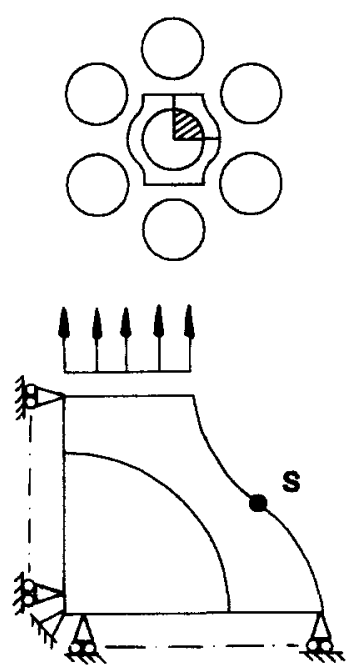

Fig. 14. Hexagonal model and finite element mesh.

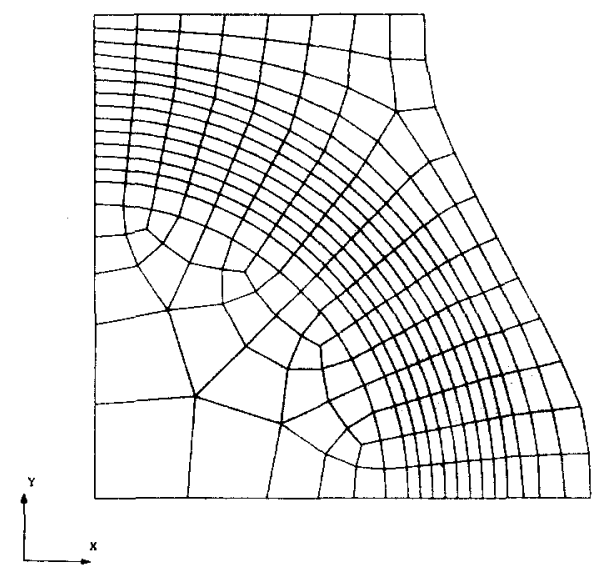



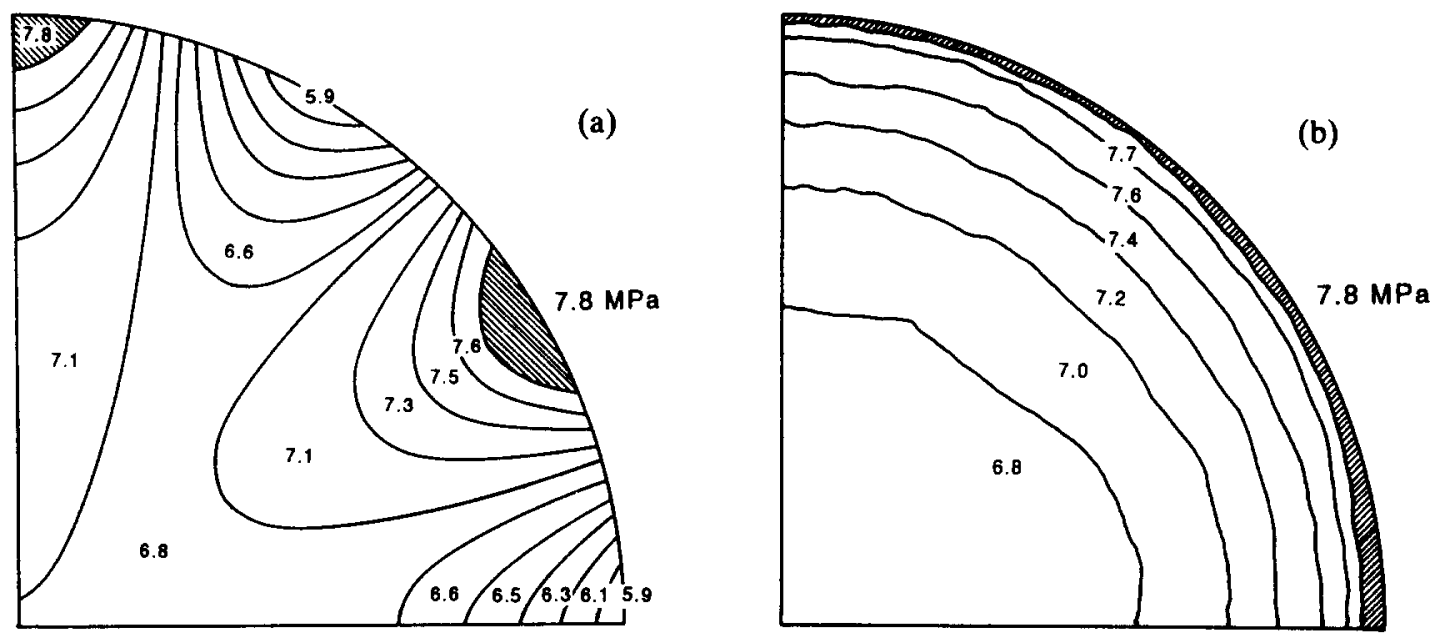

Fig. 15. Thermal residual stress distribution in HP-PE fibre after cooldown from $110^{\circ} \mathrm{C}$ to $20^{\circ} \mathrm{C}\left(\Delta T=90^{\circ} \mathrm{C}\right)$ and no external load applied: (a) radial stress; (b) maximum principle stress.

$\left(\Delta T=0^{\circ} \mathrm{C}\right)$, a maximum principle stress in the fibre of about $9 \mathrm{MPa}$ is calculated. Interesting to note is that, for $E_{\mathrm{f}}<E_{\mathrm{m}}$, the highest value for the principal stress occurs near the equator of the fibre, $90^{\circ}$ from the transverse loading axis, whereas generally (in the case of $E_{\mathrm{f}}>E_{\mathrm{m}}$ ) the highest stress concentration occurs at the pole of the fibre. ${ }^{53}$

Taking the stress concentrations into account as calculated via FEM, the stress for transverse fibre splitting in HP-PE/epoxy composites, assuming perfect adhesion, can be predicted by

$$
\sigma_{22}=\frac{\sigma_{22 \mathrm{f}}-\sigma_{\Delta T}}{\mathrm{SCF}}
$$

where $\sigma_{22 \mathrm{f}}$ is the transverse fibre strength, $\sigma_{\Delta T}$ and SCF are the thermally induced stress and maximum stress concentration factor, respectively, as obtained from the finite element analysis.

Using an SCF of 0.9 (Fig. 16), a thermally induced

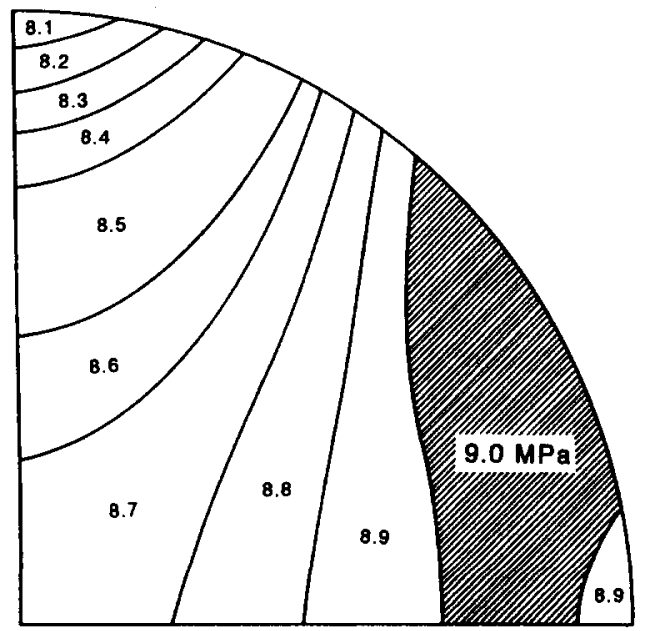

Fig. 16. Maximum principle stress in HP-PE fibre if an external load of $10 \mathrm{MPa}$ is applied to the composite $\left(\Delta T=0^{\circ} \mathrm{C}\right)$. stress of $7.8 \mathrm{MPa}$ (Fig. 15(b)) and a transverse fibre strength of $14 \mathrm{MPa}$ (Table 3), the predicted stress for fibre splitting in HP-PE composites with perfect adhesion yields a value of $7 \mathrm{MPa}$. If no thermal stresses are taken into account this failure stress is $16 \mathrm{MPa}$. Both these values are fairly close to the experimentally observed transverse tensile strength of the plasma-treated composites (8-11 MPa) and clearly quantify the role of the low lateral fibre strength on the ultimate transverse composite strength. Since both fibre and composite possess similar values for transverse strength this also suggests that composite failure is strongly controlled by failure initiation within the fibre, i.e. a 'strength-of-materials' failure concept where the composite strength is limited by either the matrix or the fibre strength magnified by a stress concentration factor. ${ }^{53,54}$

\subsection{Shear strength: influence of adhesion on strength and failure mode}

Table 8 lists the measured shear strengths of HP-PE/epoxy composites. The in-plane shear strength $\left(\tau_{12}\right)$ was determined from two types of shear tests, viz. $5^{\circ}$ off-axis and $\pm 45^{\circ}$ tension. For the $5^{\circ}$ off-axis test the shear stress was determined from the maximum applied stress $\left(\sigma_{\theta}\right)$ at an angle $\theta$, using eqn (11). The shear stress for a uniaxial test on a $\pm 45^{\circ}$ laminate is given by

$$
\tau_{12}=\frac{\sigma_{\theta}}{2}
$$

For a comparison we also measured the ILSS $\left(\tau_{13}\right)$ as determined using the short-beam shear test, the geometry of which is designed to cause the composite to fail in shear. The ILSS is given by

$$
\text { ILSS }=\frac{3 P}{4 w t}
$$


Table 8. Shear strengths of HP-PE/epoxy composites

\begin{tabular}{lcc}
\hline & $\begin{array}{c}\text { Untreated HP-PE, } \\
\tau(\mathrm{MPa})\end{array}$ & $\begin{array}{c}\text { Treated HP-PE, } \\
\tau(\mathrm{MPa})\end{array}$ \\
\hline $5^{\circ}$ Off-axis $\left(\tau_{12}\right)$ & 6 & 17 \\
$\pm 45^{\circ}$ Tension $\left(\tau_{12}\right)$ & 10 & 18 \\
ILSS $\left(\tau_{13}\right)$ & 14 & 30 \\
\hline
\end{tabular}

where $P$ is the failure load, $w$ is the width, and $t$ is the thickness of the specimen.

As shown in Table 8, fibre surface treatment also resulted in an increase in shear strength. In-plane $(1,2)$ shear strength increased by 180 and $80 \%$ for the $5^{\circ}$ off-axis and $\pm 45^{\circ}$ tensile test, respectively. Short beam shear tests yielded the highest values for the composite shear strength and showed an increase of $110 \%$ with fibre surface treatment. The relatively low shear strength as obtained by the $5^{\circ}$ off-axis test can be explained by the fact that in off-axis testing of UD

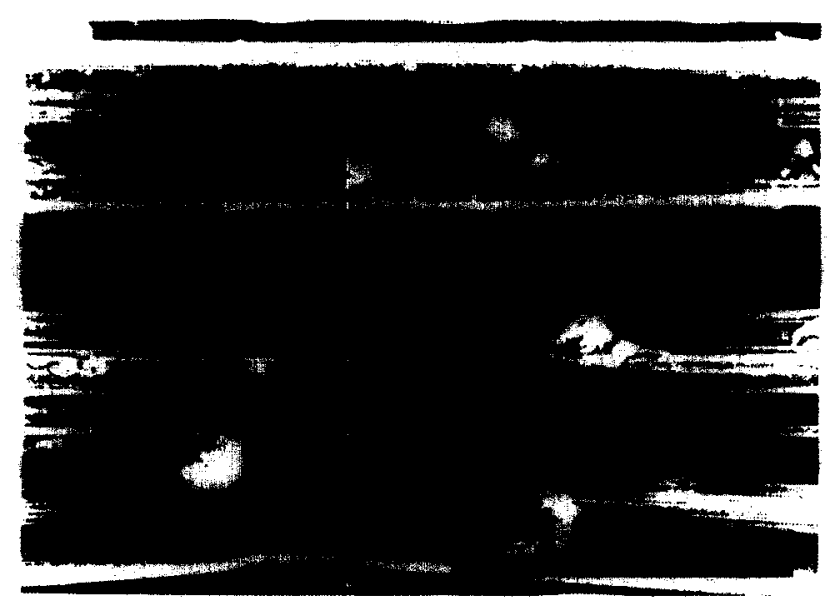

(a)

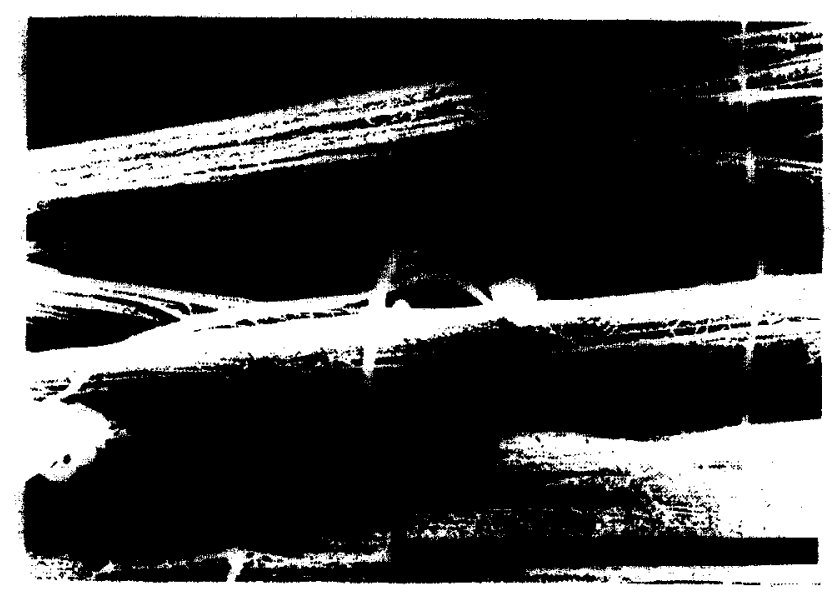

(b)

Fig. 17. SEM of ILSS fracture surface of: (a) untreated composite showing debonding, and (b) surface of treated composite showing fibre splitting. composites, strength is strongly determined by flaws and can be regarded as a weakest link type of failure process, whereas in the other tests failure is more of a progressive nature and less controlled by one single defect. Furthermore, it is well known that the ILSS value only gives a qualitative value for shear strength since failure is often a combination of different failure modes, such as multiple delamination, local crushing by the load pin, compressive failure, etc. All these effects will result in a non-uniform state of shear stress. ${ }^{55}$

Similar to the change in failure mode as observed in the transverse tensile test, in shear a change in failure mode from total debonding (Fig. 17(a)) to fibre splitting and/or fibrillation (Fig. 17(b)) is also observed. Figure 17(a) shows a typical HP-PE fibre showing debonding after an ILSS test. Composites incorporating surface-treated HP-PE fibres showed a subsequent increase in short-beam shear strength from 14 to $30 \mathrm{MPa}$ and fibre splitting (Fig. 17(b)), indicating that, in shear also, composite properties are fibre dominated rather than interface dominated.

\subsection{Compressive strength}

\subsubsection{Influence of adhesion on strength and failure mode}

Although improved adhesion resulted in a significant increase $(25 \%)$ in longitudinal compressive strength of HP-PE/epoxy composites, values for the compressive strength of treated HP-PE composites (91 MPa) are still very low compared to those of other composite systems. ${ }^{45,46}$ Figure 18 shows that composites with untreated fibres fail in a more brittle way, whereas composites incorporating treated HP-PE fibres show a more ductile character with a clear yield point.

To study the influence of improved adhesion on the failure modes of HP-PE/epoxy composites in compression, longitudinal sections of tested samples were polished for optical microscopic examination. These sections revealed characteristic differences between composites with untreated and treated fibres. Composites with untreated fibres failed by longitudinal splitting and showed only little kinking (Fig. 19(a)), whereas with improved adhesion the failure mode changed to more severe kinking with a highly 


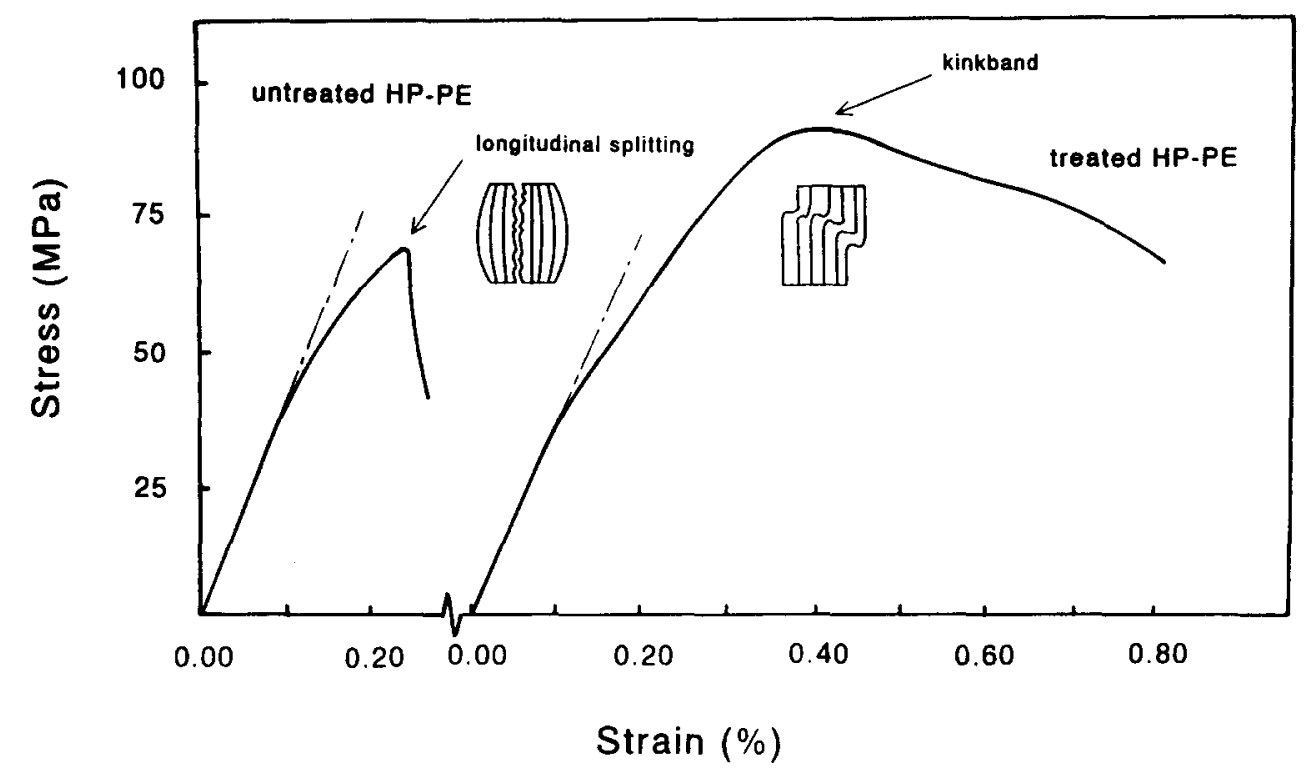

Fig. 18. Typical stress/strain curves for unidirectional HP-PE/epoxy composites in longitudinal compression.

localized kink band (Fig. 19(b)). Therefore, it appears that the increase in compressive strength of HP-PE composites incorporating surface treated fibres is caused by this change in failure mode.

\subsubsection{Micromechanics: ultimate properties}

The compressive strength of composites consisting of ductile fibres cannot be explained by theories that assume failure due to fibre buckling. ${ }^{56}$ The compressive strength in this type of composite is often dominated by the compressive yield stress of the fibres. Assuming plastic behaviour of the fibres, for aramid and metal fibre-based composites, the compressive strength is reasonably good as described by a simple ROM relationship: ${ }^{57}$

$$
\sigma_{11 \mathrm{c}}=\sigma_{\mathrm{fc}} V_{\mathrm{f}}+\sigma_{\mathrm{mc}}\left(1-V_{\mathrm{f}}\right)
$$

where $\sigma_{\mathrm{fc}}$ is the compressive yield stress of the fibre, and $\sigma_{\mathrm{mc}}$ is the compressive strength or yield stress of the matrix. Compressive failure in the fibre is accompanied by the appearance of so-called kinkbands, i.e. buckling on the compressive face of the fibre (Fig. 20) and is comparable with failure processes found in other polymeric fibres such as aramid. ${ }^{58,59}$ The formation of such kinkbands is strongly dominated by the low shear properties of the fibre, which means that the compressive strength of fibres is directly related to fibre anisotropy.

In order to determine the compressive yield stress of HP-PE fibres, single fibres were subjected to so-called 'elastica' loop tests. ${ }^{58}$ Loops with a diameter of about $50 \mathrm{~mm}$ were placed in silicone oil between glass slides. The fibre ends were led out of the ends of the slides, and the size of the loop was reduced in stages by pulling the ends of the fibre. The major axis $c$ and the minor axis $a$ were measured accurately at each stage. In theory, the ratio of major to minor axis should stay constant and equal to 1.34 as long as the fibre behaves elastically. ${ }^{58}$ The compressive yield stress of the fibre was obtained from the stress at which the fibre lost its elastic properties, and the ratio of the major axis to minor axis deviated from its constant value. This yield stress can be calculated by

$$
\sigma_{\mathrm{fc}}=\frac{1.34 E_{\mathrm{fc}} d}{c_{\mathrm{crit}}}
$$

where $E_{\mathrm{fc}}$ is compressive modulus of the fibre, $d$ is the fibre diameter, and $c_{\text {crit }}$ is the major axis of the loop at which $c / a$ increases sharply (see Fig. 21).

By assuming a compressive modulus $E_{\mathrm{fc}}$ of about $50 \mathrm{GPa}$, i.e. similar to the tensile modulus at low strain rates $\left(10^{-5}-10^{-6} \mathrm{~s}^{-1}\right),{ }^{2,3}$ a mean fibre diameter $d$ of $27 \mu \mathrm{m}$ and a $c_{\text {crit }}$ of $30 \mathrm{~mm}$, the compressive strength of a HP-PE fibre yields about $60 \mathrm{MPa}$, which is only $2 \%$ of the tensile strength. Using eqn (18) and a compressive strength for the epoxy matrix of $120 \mathrm{GPa}$, the compressive strength of a composite with a fibre volume fraction of 0.5 yields about $90 \mathrm{MPa}$, which is in good agreement with the experimental data for the compressive strength of HP-PE composites incorporating treated fibres, indicating that also in compression the strength of HP-PE composites is limited by the fibre rather than the interface.

\section{CONCLUSIONS}

In this study it was attempted to obtain more insight into the role of adhesion and the highly anisotropic character of HP-PE fibres on the strength of composite laminates based on HP-PE fibres. It was concluded that properties such as transverse, shear 


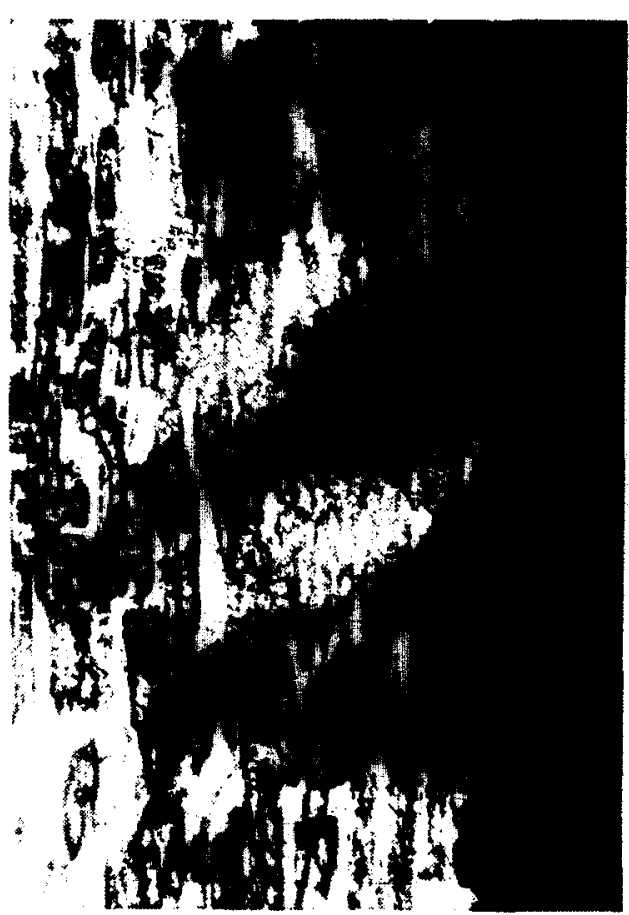

(a)

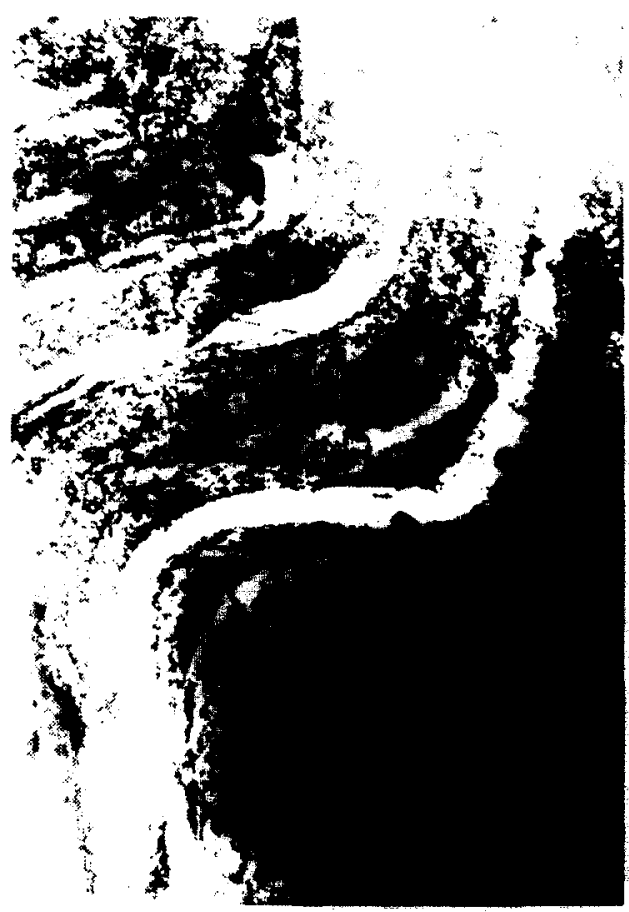

(b)

Fig. 19. Optical micrographs of polished sections of compression tested specimens: (a) untreated HP-PE composite; (b) treated HP-PE composite.

and compressive strengths of HP-PE/epoxy composites are dominated by the fibre rather than the interface, which implies that not adhesion but fibre anisotropy is the key issue in preventing the use of these fibres in structural applications.

This conclusion is based on fractographic studies on off-axis loaded composites, which showed with increasing levels of adhesion a change in failure mode

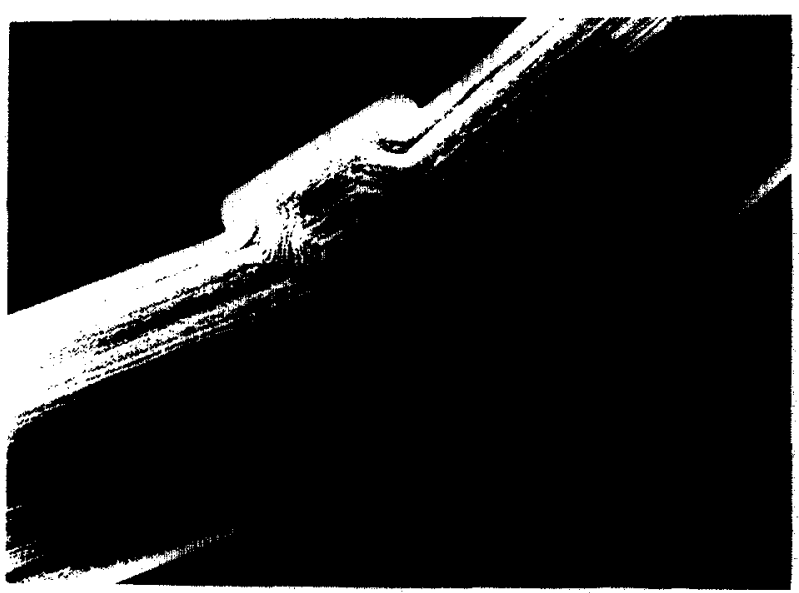

Fig. 20. SEM micrograph of kinkband in a HP-PE filament.

from debonding to fibre fibrillation and fibre splitting, suggesting fibre dominated properties rather than the interfacial dominated properties in the case of composites based on plasma-treated HP-PE fibres. More quantitative information on the role of fibre anisotropy was obtained from off-axis tensile testing of ultradrawn UHMW-PE tapes, which was used as an alternative to off-axis fibre testing. These tests showed that the off-axis properties of HP-PE/epoxy composites with a good fibre/matrix bond strength are similar to the off-axis strength of ultradrawn UHMW-PE tapes, meaning that transverse and shear properties of the composites are controlled by the highly anisotropic character of the fibre. Also in compression the strength of HP-PE composites is dominated by the low compressive yield stress of the fibre rather than by the interface.

Consequently, the usefulness of developments in

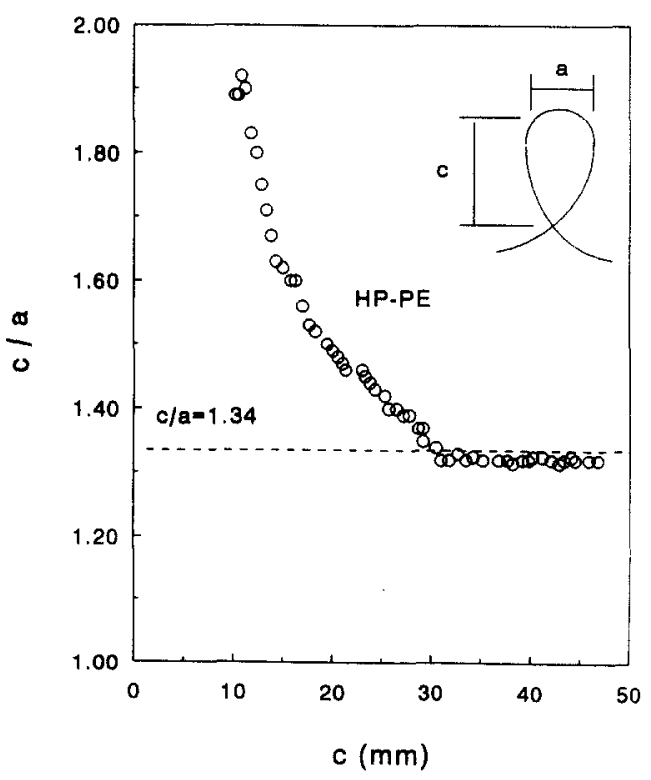

Fig. 21. Typical ratio of major to minor axis in a loop test for HP-PE fibre. The ratio $c / a$ increases sharply when the major axis is reduced below $30 \mathrm{~mm}$. 
the area of surface treatments to improve the applicability of HP-PE fibres in structural composites, as frequently described in the literature, is highly questionable. Given the highly anisotropic properties of HP-PE fibres, their structural applications are limited and attempts to improve their applicability by improving the adhesive bond between fibre and matrix are consequently not relevant. In fact, since in the case of HP-PE fibre surface treatment generally results in a reduction in impact performance, ${ }^{60,6} \mathrm{a}$ poor bond strength might even be desirable since most applications focus on energy absorption and ballistic protection. Also, with respect to attempts to transform the highly anisotropic, 1-D, fibre of HP-PE into a less anisotropic, 'X-D', character (for example, via cross-linking of $\mathrm{PE}^{62}$ by the use of other more polar polymers such as poly(vinyl alcohol) $)^{63}$ in order to shift the barrier which limits structural performance, one should bear in mind that for many properties ' $\mathrm{X}$ ' has to stand for two-plus rather than one-plus. Even in the case of composites based on poly(vinyl alcohol) fibres $^{63}$ possessing hydrogen bonds between the chains, which are strong compared to the relatively weak Van der Waals interactions in PE fibres, only marginal improvements in structural performance were obtained.

\section{REFERENCES}

1. Lemstra, P. J., Kirschbaum, R., Ohta, T. \& Yasuda, H., In Developments in Oriented Polymers-2, ed. I. M. Ward. Elsevier Applied Science, London, 1987, p. 39.

2. Govaert, L. E., Bastiaansen, C. W. M. \& Leblans, P. J. R., Polymer, 34(3) (1993) 534.

3. Peijs, T., Smets, E. A. M. \& Govaert, L. E., Appl. Comp. Mater. (in press).

4. Lin, L. C., Bhatnagar, A., Lang, D. C. \& Chang, H. W., Proc. 33rd Int. SAMPE Symp., Anaheim, CA, 1988.

5. Peijs, A. A. J. M., Venderbosch, R. W. \& Lemstra, P. J., Composites, 21(6) (1990) 522.

6. Adams, D. F., Zimmerman, R. S. \& Chang, H. W., SAMPE J., 21(6) (1985) 44.

7. Ladizesky, N. H. \& Ward, 1. M., J. Mater. Sci., 18 (1983) 533.

8. Nardin, M. \& Ward, I. M., Mater. Sci. and Technol., 3 (1987) 814.

9. Ladizesky, N. H. \& Ward, I. M., J. Mater. Sci., 24 (1989) 3763.

10. Ladizesky, N. H. \& Ward, I. M., Comp. Sci. and Technol., 26 (1986) 129.

11. Ladizesky, N. H., Sitepu, M. \& Ward, I. M., Comp. Sci. and Technol., 26 (1986) 169.

12. Tissington, B., Pollard, G. \& Ward, I. M., Comp. Sci. and Technol., 26 (1991) 82.

13. Burlet, R. J. H., Raven, J. H. H. \& Lemstra, P. J., Eur. Pat. Appl. EP 144997 A2, DSM Stamicarbon (1985).

14. Jacobs, M. J. N. \& Rutten, H. J. J., Eur. Pat. Appl. EP 311198 A2, Dyneema Vof (1989).

15. Kaplan, S. L., Rose, P. W., Nguyen, H. X. \& Chang, H. W., SAMPE Q., 19(4) (1988) 55.

16. Nguyen, H. X., Riahi, G., Wood, G. \& Poursartip, A., 33rd Int. SAMPE Symp., 1988, p. 1721.
17. Nguyen, H. X., Weedon, G. C. \& Chang, H. W., 34th Int. SAMPE Symp., 1989, p. 1603.

18. Jacobs, M. J. N. \& Rutten, H. J. J., Eur. Pat. Appl. EP 311197 A2, Dyneema Vof (1989).

19. Tissington, B., Pollard, G. \& Ward, I. M., J. Mater. Sci., 26 (1991) 82.

20. Boogh, L. C. N., Meier, R. J., Kausch, H. H. \& Kip, B. J., J. Polymer Sci.; Part B: Polymer Phys., 30 (1992) 325 .

21. Michaeli, W. \& Londschien, M., In Interfacial Phenomena in Composite Materials ' 91 , ed. I. Verpoest \& F. Jones. Butterworth-Heinemann, London, 1991 p. 30.

22. Holmes, S. \& Schwartz, P., Comp. Sci. and Technol., 38(1) (1990) 1.

23. Li, Z. F. \& Netravali, A. N., J. Appl. Polymer Sci., 44 (1992) 333.

24. Ulcay, Y., Pourdeyhimi, B. \& Block, I., Comp. Eng., 1(3) (1991) 145.

25. Postema, A. R., Doornkamp, A. T., Meijer, J. G. \& Van de Vlekkert, H., Polymer Bull., 16 (1986) 1.

26. Mercx, F. P. M., Benzina, A., Langeveld, A. D. \& Lemstra, P. J., J. Mater. Sci., 28 (1993) 753.

27. Mercx, F. P. M., Polymer, 34 (1993) 1981.

28. Mercx, F. P. M., Polymer, 35 (1994) 2098.

29. Dobb, M. G., Johnson, D. J. \& Saville, B. P., Phil. Trans, Roy. Soc. London, A, 294 (1979) 483.

30. Allen, S. R. \& Farris, R. J., Polymer, 31 (1990) 1467.

31. Singer, L. S., In Ultra-High Modulus Polymers, ed. A. Ceferi \& I. M. Ward. Applied Science, London, 1979, p. 251.

32. Blakslee, O. L., Proctor, D. G., Seldin, E. J., Spence, G. B. \& Weng, T., J. Appl. Phys., 41 (1970) 3373.

33. Bunsell, A. R., Composite Material Series-2, Elsevier, Amsterdam, 1988, Chap. 10.

34. Norita, T., Kitano, A. \& Noguchi, T., Proc. American Society of Composite Materials, 1988, p. 548.

35. Allen, S. R., Filippov, A. G., Farris, R. J. \& Thomas, E. L., 37th SPI Annual Conf., 1982, p. 24B.

36. Phoenix, J. L. \& Skelton, J., Text. Res. J., 44(12) (1974) 934.

37. Kawabata, S., Sera, M., Kotani, T., Katsuma, K., Niwa, M. \& Xiaoxin, C., In Proc. 9th Int. Conf. on Composite Materials $(I C C M / 9)$, Vol. VI, ed. A. Miravete. Woodhead, 1993, p. 671.

38. McGarry, F. J. \& Moalli, J. E., Polymer, 32 (1991) 1881 and 1816.

39. Tashiro, K., Kobayashi, M. \& Tadokoro, H., Macromolecules, 11 (1978) 914.

40. Nakamae, K. \& Nishino, T., In Integration of Polymer Science and Technology-3, ed. P. J. Lemstra \& L. Kleintjes. Elsevier Applied Science, London, 1985.

41. Govaert, L. E., Brown, B. \& Smith, P., Macromolecules, 25(13) (1992) 3480.

42. Bastiaansen, C. W. M., Leblanc, P. J. R. \& Smith, P., Macromolecules, 23 (1990) 236.

43. Lemstra, P. J., van Aerle, N. A. J. M. \& Bastiaansen, C. W. M., Polymer J., 19 (1987) 85.

44. Hashin, Z., J. Appl. Mech., 46 (1979) 543.

45. Tsai, S. W. \& Hahn, H. T., Introduction to Composite Materials, Technomic, Westport, 1980.

46. Tsai, S. W., Composite Design, Think Composites, Dayton, OH, 1987.

47. Scholle, K. F. M. G. J., Jacobs, M. J. N., Omloo, H. A. A., Loete, G. J. H. \& Janse, G. H. A., In New Generation Materials and Processes, ed. F. Saporiti et al. Grafiche F. B. M., Milan, 1988, p. 253.

48. Azzi, V. D. \& Tsai, S. W., Exp. Mech., 5 (1965) 283. 
49. Chamis, C. C. \& Sinclair, J. H., NASA TN D-8215, 1976.

50. Valentin, D., Composites, 14(4) (1983) 345.

51. Adams, D. F. \& Doner, D. R., J. Comp. Mater., 1 (1966) 155.

52. MARC Manual, Marc Analysis Research Corp., Palo Alto, CA, 1992.

53. Chamis, C. C., In Composite Materials, Vol. 5, ed. L. J. Broutman. Academic Press, New York, 1974, p. 126.

54. de Kok, J. M. M., van Klinken, E. J. \& Peijs, A. A. J. M., In Advanced Composites '93, ed. T. Chandra \& A. K. Dhingra. The Minerals, Metals \& Materials Society, 1993 , p. 427.

55. Berg, C. A., Tirosh, J. \& Israeli, M., Composite Materials: Testing and Design 2nd Conf., ASTM STP 497, 1972, p. 206.

56. Rosen, B. W., Mechanics of Composite Materials,
American Society for Metals, Ohio, 1965, p. 37.

57. Hull, D., An Introduction to Composite Materials, Cambridge University Press, Cambridge, 1981.

58. Dobb, M. G., Johnson, D. J. \& Saville, B. P., Polymer, 22 (1981) 960.

59. Greenwood, J. H. \& Rose, P. G., J. Mater. Sci, 9 (1974) 1809.

60. Peijs, A. A. J. M., Catsman, P. \& Venderbosch, P. W., In Composite Structures-6, ed. I. H. Marshall. Elsevier Applied Science, London, 1991, p. 585.

61. Peijs, A. A. J. M., Venderbosch, R. W. \& Lemstra, P. J., Composites, 21 (6) (1990) 522.

62. Ward, I. M. \& Wilding, M. A., J. Polym. Sci., Polym. Phys. Ed., 22 (1984) 561.

63. Peijs, T., van Vught, R. J. M. \& Govaert, L. E., Composites (in press). 